\title{
EL NÚCLEO HISTÓRICO DE BELLAVISTA COMO ZONA MONUMENTAL: ANÁLISIS URBANO-ARQUITECTÓNICO ${ }^{(*)}$
}

\author{
THE HISTORICAL CENTER OF BELLAVISTA AS A MONUMENTAL AREA: URBAN - \\ ARCHITECTURAL ANALYSIS \\ PATRICIA MALPARTIDA PACAYA ${ }^{(\star x}$ \\ (D) https://orcid.org/0000-0003-0297-1401 \\ patty.malpartida16@gmail.com \\ Grupo de investigación en patrimonio cultural Yuyai-UNI, Universidad Nacional de Ingeniería (Perú)
}

\author{
Fecha de recepción: 1 de mayo de 2019 \\ Fecha de aprobación: 16 de enero de 2020
}

\section{RESUMEN}

El Núcleo Histórico de Bellavista, diseñado por Luis Godín en 1747, desde hace unas décadas sufre un proceso de degradación que se da por abandono, deterioro, cambio de usos de suelo, demoliciones, entre otros factores. La Bellavista histórica de arquitectura colonial y republicana, con el paso del tiempo empieza a desaparecer en desmedro de su imagen urbana que posee un gran valor tanto para la historia del Callao como para la historia de Lima. Lamentablemente, poco se ha investigado sobre las edificaciones antiguas en este distrito. Por eso mismo, en este artículo daremos a conocer los estudios urbanos y arquitectónicos que identifican los valores del Núcleo Histórico de Bellavista con el fin de hacer posible una declaración de monumentos que ponga en valor la zona histórica del distrito y frenar, en lo posible, este proceso de degradación que atraviesa. La presente investigación se la dedico al distrito que me vio crecer, Bellavista, mi hogar.

\section{PALABRAS CLAVE}

Callao; Valoración urbano-arquitectónica; Zona Monumental de Bellavista

\section{ABSTRACT}

The Historic Center of Bellavista, designed by Luis Godín in 1746, is in a process of degradation that has been occurring for several decades due to various factors such as abandonment, deterioration, change of land uses, demolitions, among others. The urban layout of the historic Bellavista, which encloses colonial and republican architecture within it, with the passage of time begins to disappear distorting the urban image that has great historical value for both the history of Callao and the history of Lima. Unfortunately there is little that has been investigated of the ancient buildings in this district, therefore, the present article reveals the urban and architectural studies that will identify the values of the Historic Center of Bellavista in order to achieve a possible declaration of monuments putting in value the historical zone of the district and stopping, as far as possible, this process of degradation that is going through. The present investigation is dedicated to the district that saw me grow up, Bellavista, my home.

\section{KEYWORDS}

Callao; Urban-Architectural Assessment; Monumental Zone of Bellavista

(*) Este artículo se desarrolló a partir de la investigación titulada La evaluación urbana y arquitectónica del Casco Histórico de Bellavista para la declaración de Monumentos, realizada en el Taller de Investigación en Historia de la Arquitectura (TIHIS I, TIHIS II), de la Facultad de Arquitectura, Urbanismo y Artes de la Universidad Nacional de Ingeniería (UNI). El artículo se desarrolló durante el año 2016 en las asignaturas bajo la responsabilidad del MSc. Arq. José Beingolea Del Carpio.

$\left.{ }^{(* *}\right)$ Bachiller en Arquitectura por la Universidad Nacional de Ingeniería. Actualmente es integrante del Grupo de investigación en patrimonio cultural Yuyai-UNI y ha participado en la investigación y elaboración de ponencias en Congresos de Arquitectura militar y fortificada organizados por el Comité Científico Internacional sobre Fortificaciones y Patrimonio Militar (Icofort) de Icomos, en Brasil (2017) y Japón (2018). 
devenir Vol. 7, N¹3, ENERO - JUNIO 2020, PP. 31-58 - ESTUDIOS I ISSN 2312-7562 | E-ISSN 2616-4949

UNIVERSIDAD NACIONAL DE INGENIERÍA, LIMA

doi: https://doi.org/10.21754/devenir.v7i13.925

El presente trabajo de investigación consiste en una evaluación del aspecto urbano y arquitectónico del Núcleo Histórico de Bellavista para dar a conocer los valores que posee y pueda servir a las autoridades pertinentes como base y referencia para una declaración de monumentos.

Partimos de la teoría que sustenta la importancia de conservar los centros históricos que crean una identidad en su población y que pone en valor al Núcleo Histórico tanto en sus edificaciones como en el aspecto urbano para que pueda ser declarado Monumento. Se aplicarán los distintos métodos para realizar el análisis arquitectónico y urbanístico, y así realizar el proceso correspondiente para evidenciar sus valores.

El éxito de este trabajo se dará si las autoridades toman acciones y promueven la creación de proyectos para la recuperación del Núcleo Histórico y contactan con las entidades correspondientes para que pueda ser declarado Zona Monumental. Al poner en valor la zona histórica del distrito se frenará en cierta manera, el proceso de degradación que tanto le afecta.

El Callao es rico en historia, cultura y patrimonio; sin embargo, no hay investigaciones sobre la Provincia Constitucional y carece de proyectos de recuperación de sus zonas históricas. Felizmente, en los últimos años se han hecho publicaciones importantes como el artículo de Marsia Montáñez en la revista Devenir N 06: "Gestión y Valoración del patrimonio histórico inmueble en el Centro Histórico del Callao"y también el proyecto de Huaca Culebras que viene realizando la DDC Callao con el fin de proteger y promover el espacio cultural en la región, proyecto reseñado pertinentemente en la publicación de la revista Devenir $N^{\circ} 10$.

En cuanto a Bellavista, a pesar de que su creación tiene un rol importante en la historia de Lima y Callao, las investigaciones son prácticamente inexistentes, la documentación bibliográfica en ciertos puntos es escasa, y en otros, nula. Sin embargo, se dispone de documentación conformada por libros, ensayos y artículos relacionados con el tema de investigación. Asimismo, me baso en mis experiencias y observación crítica como pobladora de este distrito por 25 años.

Se cuenta con cierta documentación de carácter gráfico sobre el diseño de la trama del Núcleo Histórico de Bellavista. Dicha documentación está conformada por planos, fotografías, grabados, etc. Al no haber mayor información, los planos de los procesos de transformación han sido elaborados por la autora (ver Figura 1).

\section{Delimitaciones del estudio}

\section{Delimitación espacial}

La delimitación espacial como referencia de estudio que se tomará en cuenta para la presente investigación es el área del Núcleo Histórico de Bellavista diseñada por Luis Godín en 1747 y alrededores, la cual limito y tomo como referencia a través del mapa del distrito que data del año en mención.

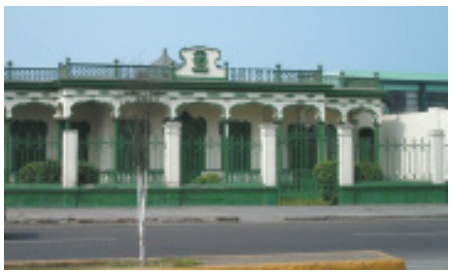

Figura 1. Edificación de existencia generalizada en el Núcleo Histórico del distrito de Bellavista. Esta edificación fue demolida para ser reemplazada por un colegio privado. Recuperado de www.callaohistorico. com, 2010.
Las avenidas delimitadoras del área histórica del distrito son:

- Por el Norte: Av. Miguel Grau y Av. Guardia Chalaca.

- Por el Sur: Calle Loreto

- Por el Este: Calle Zarumilla

- Por el Oeste: Calle Espinar

\section{Delimitación temporal}

La investigación estudiará el patrimonio arquitectónico monumental que fue construido desde la creación del distrito, es decir, se tomará en cuenta desde el año de 1747 y cómo se ha ido transformando hasta el año 2016. 


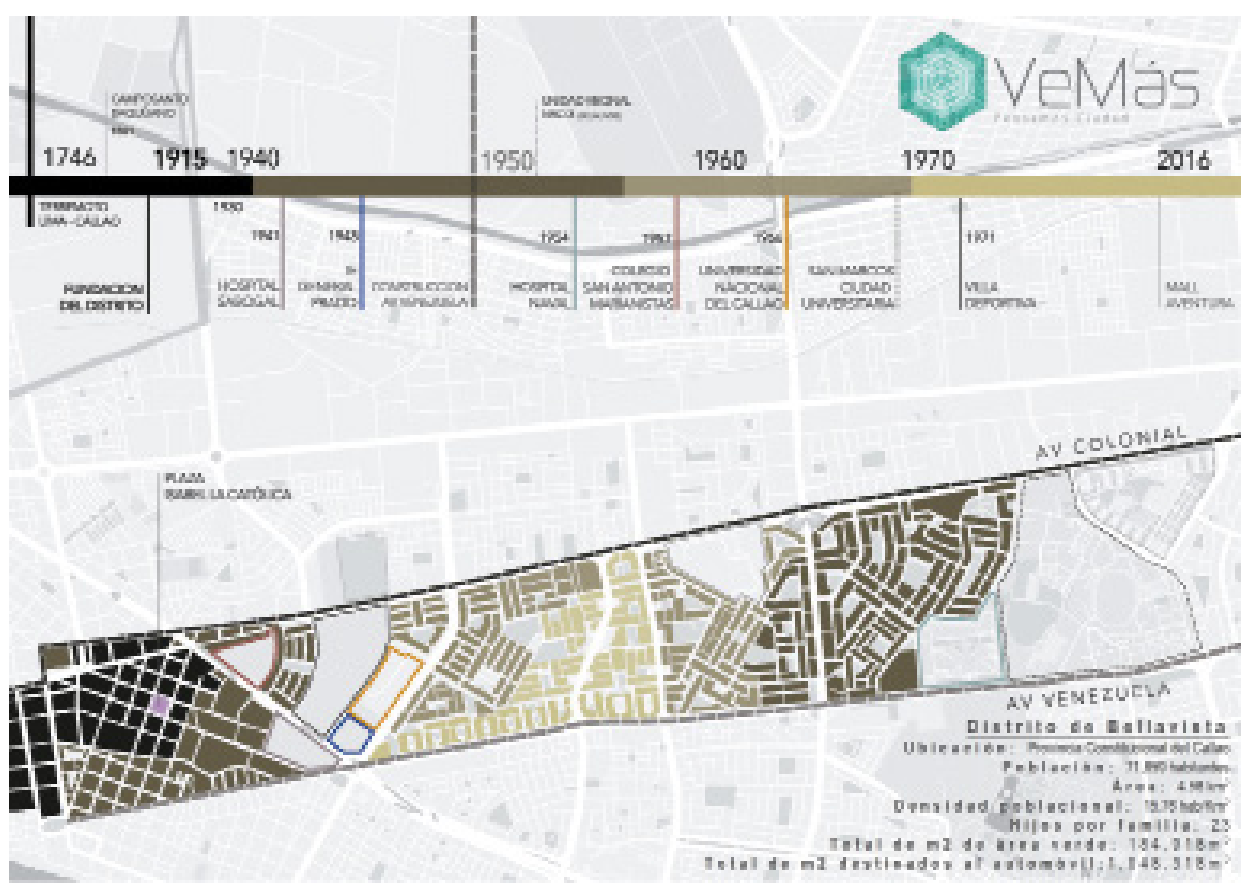

Figura 2. Plano de Bellavista con línea del tiempo donde se mencionan las construcciones más emblemáticas del distrito. Recuperado de https://www.ve-mas.com/bellavista-en-la-mira-gran-potencial-para-invertir/, 2019.

\section{Marco contextual}

Bellavista es uno de los siete distritos que conforman la Provincia Constitucional del Callao. Es el segundo distrito con mayor antigüedad de la provincia chalaca y uno de los más antiguos de Lima. Según los datos de la Municipalidad de Bellavista, "su elevación distrital se dio el 6 de octubre de 1915 mediante la ley № 2141, la cual también creó el distrito de La Punta".

Es un distrito residencial consolidado donde se pueden distinguir 4 zonas residenciales diferentes: Cercado de Bellavista (Sector histórico); Ciudad del Pescador; Urb. Virú y aledaños; y Urb. San Joaquín - San José (ver Figura 2).

\section{Dirección Desconcentrada de Cultura del Callao como marco institucional}

El Director de la Dirección de Desconcentrada de Cultura-Callao (DDC-Callao) a nivel regional y en coordinación con las políticas y disposiciones del Ministerio de Cultura, ejerce la función de normar, conservar, promover y difundir el patrimonio cultural del Callao, apoyando las diversas manifestaciones culturales y realizando acciones que contribuyan al desarrollo cultural de la población del Callao, propiciando su participación activa.

Promueve la identificación, estudio, defensa, puesta en valor y difusión del patrimonio cultural material e inmaterial, mueble e inmueble de la jurisdicción.

\section{Marco conceptual: Patrimonio, Centros Históricos y Paisaje}

\section{Patrimonio y arquitectura menor}

Un paso gigante en el concepto de patrimonio lo da Gustavo Giovannoni -importante continuador de Camilo Boito en el primer tercio del siglo XX — cuando "reacciona contra el aislamiento urbano de los monumentos ((lo contrario a lo que había definido Violletle-Duc) y contra la falta de estimación por los conjuntos urbanísticos y, en general, por 
la arquitectura menor" (Capitel, 2009, p. 39). Pues, como argumentaba Giovannoni, sin el entorno, no se podría entender la relación espacial y volumétrica, como la simbólica y la formal, entre un castillo y el caserío que lo rodeaba.

Con la defensa elaborada por Giovannoni de las arquitecturas menores (luego extendidas e incorporadas como populares y vernáculas) se toma conciencia de que una población podía tener un patrimonio sin grandes monumentos pero si una arquitectura de conjunto tan valiosa como aquellas otras que poseían grandes catedrales o monasterios de enorme significación en la Edad Media y Edad Moderna. Es el caso de Brujas, ciudad belga de belleza singular que muestra un gran valor histórico por su conjunto de edificios pertenecientes a una misma época y con similares características arquitectónicas de armonía formal, visual y urbana.

Similar al caso de Brujas, se puede aplicar el concepto de Giovannoni en el Núcleo Histórico de Bellavista puesto que, a pesar de que no cuente con grandes edificios o monumentos como lo tiene el Centro Histórico de Lima o el Callao Monumental, su arquitectura menor en conjunto forman un paisaje característico en la zona, evidencia de la historia que tuvo el distrito.

\section{Patrimonio y paisaje}

El profesor Javier Maderuelo, un gran especialista en paisajismo, señala que el paisaje depende de la percepción y de la visión del medio rural y por extensión del medio urbano. Sostiene, además, que "el paisaje es dinámico y cambiante y es preciso intervenir en él, pero siempre con equilibrio, tratando de conseguir que las innovaciones que exige nuestro tiempo se estudien con el máximo rigor al aplicar a un espacio o paisaje catalogado" (Maderuelo, 2010, p. 27). Para observar estos cambios podemos utilizar los dibujos y/o fotografías porque gracias a estos documentos tenemos testimonios del paso del tiempo en los paisajes y de sus transformaciones. Y, finalmente, se deberían analizar las mutaciones del paisaje en virtud de sus alteraciones positivas o negativas (degradaciones, mejoras, etcétera). Así se tendría constancia de las transformaciones físicas de los paisajes. Y también de su utilidad para ahondar en el conocimiento de este tema.

La metodología de análisis del paisaje de Maderuelo propone que la vinculación con el territorio y el patrimonio se debe realizar desde tres horizontes: 1.- A nivel territorial a través de la escala municipal o el paisaje concreto tomándolo como unidad básica. 2.- A escala urbana en los núcleos habitados y 3.- A escala arquitectónica; estudiando con detenimiento los elementos relevantes presentes en cada uno de ellos, así como la relación existente entre los mismos. De esta manera se comprende e interpreta el paisaje como una síntesis del territorio que se basa en la vida y el trabajo acumulado sobre un espacio (en sus diferentes aspectos: histórico, antropológico y geográfico).

A su vez, hace reflexiones sobre la valoración del paisaje, la cual

(...) se suele abordar desde dos perspectivas marcadamente diferentes, aunque a menudo complementarias: la científica y la social. La primera se realiza por especialistas en paisaje... La segunda es la realizada por el común de la población, generalmente a través de encuestas o entrevistas. La científica se realiza mediantes sistemas indirectos, a través de distintos factores o indicadores, mientras que la social se asocia a sistemas valorativos directos, en los que la percepción de la estética o de la belleza del paisaje es clave. (Maderuelo, 2010, p. 81).

Para la valoración de la calidad del paisaje, Javier Maderuelo propone:

1.- Delimitar las unidades del paisaje.

2.- Los tipos de paisaje que encontramos.

3.- Los impactos negativos a lo largo del tiempo. 
4.- Identificar las singularidades paisajísticas.

5.- La visibilidad que tiene este paisaje desde otros puntos del territorio.

6.- Una vez identificados los puntos anteriores, se puede evaluar la calidad del paisaje.

"Nuestra propuesta consta de un conjunto de fases secuenciales de manera que la final valorativa no puede entenderse sin las previas" (Maderuelo, 2010, p. 84).

Dichos criterios se toman en cuenta para la valoración del paisaje debido al emplazamiento que tuvo Bellavista durante su creación.

\section{Valores patrimoniales}

Para poder hablar de valor patrimonial, primero debemos definir lo que significa bien, valor y patrimonio.

En cuanto a un bien, se puede entender como "condición material o inmaterial, valor positivo base de una estimación y referenciación a un objeto de derecho de alguien" (Hayakawa, 2012, p. 1).

"El valor es entendido como el 'grado de utilidad o aptitud de las cosas, para satisfacer las necesidades o proporcionar bienestar o deleite......." (Hayakawa, 2012, p.2). El valor se vincula con el bien, por lo cual "se configura una cualidad por lo cual son estimables" (Hayakawa, 2012, p.2).

Según el Ministerio de Cultura, patrimonio se puede definir como la herencia de cualquier bien, material o inmaterial, que nuestros antepasados han dejado a lo largo de la historia y que se transmite de generación en generación.

Por otro lado, valor patrimonial, en términos generales, se entiende como cada una de las cualidades por las cuales un bien es estimable.

(...) como así lo refiere Josep Ballart, pues cuando hablamos de patrimonio hablamos de bien y por lo tanto de valor como '(...) aprecio hacia determinados objetos por el mérito que atesoran, por la utilidad que manifiestan, o por su aptitud para satisfacer necesidades o proporcionar bienestar. Por todo eso el valor no es siempre inherente a las cosas(...) Se trata, (...) de un concepto relativo sometido a los vaivenes de la percepción y del comportamiento humanos y, por lo tanto, dependiente de un marco de referencias intelectuales, históricas, culturales y psicológicas que varía con las personas y los grupos que atribuyen valor'(...) (Hayakawa, 2012, p. 2).

El valor vinculado al patrimonio se puede clasificar en tres tipos de acuerdo a la propuesta teórica de Josep Ballart:

- Valor de uso: Se entiende como uso para algo y satisface "una necesidad material o de conocimiento o deseo" (Hayakawa, 2012, p. 2).

- Valor formal: Cuando determinados objetos son apreciados "por la atracción que despiertan a los sentidos, por el placer que proporcionan, por razón de la forma y por otras cualidades sensibles, y por el mérito que presentan" (Hayakawa, 2012, p. 2).

- Valor simbólico - significativo: Es la consideración en que se tiene a ciertos bienes “(...)en tanto que son sustitutos de algo que no existe, es decir, de algo del pasado y no del presente, sea esto una persona, una historia, un hecho o una idea" (Ballart et al., 1996, p. 216).

"A estas tres categorías se puede adjudicar diversos subvalores." (Montañez, 2016, p. 101). 
devenir Vol. 7, N¹3, ENERO - JUNIO 2020, PP. 31-58 - ESTUDIOS I ISSN 2312-7562 | E-ISSN 2616-4949

UNIVERSIDAD NACIONAL DE INGENIERÍA, LIMA

doi: https://doi.org/10.21754/devenir.v7i13.925

\begin{tabular}{cc} 
Tabla 1. Comparación de valores patrimoniales según \\
la propuesta de J. Ballart y la del Mincult \\
\hline Equivalencia de valores patrimoniales \\
\hline J. Ballart & Mincult \\
\hline Uso & Social \\
Formal & Artístico \\
& Contextual \\
Simbólico & Histórico \\
& Cultural \\
\hline Elaboración propia, 2019.
\end{tabular}

\section{Ministerio de Cultura}

El Ministerio de Cultura (Mincult) indica que una edificación para que pueda ser declarada monumento debe tener los siguientes valores:

- Histórica: Se constata la época a la que perteneció el edificio: Colonial, Republicana, época de Transición o Moderna. Además, si en el edificio han ocurrido eventos de interés.

- Cultural: Referidos a la identidad y al valor educativo que posee el edificio.

- Social: Incluye la interacción social con la comunidad y la importancia de la identidad cultural y social.

- Artístico: Se analizan los detalles del edificio, como las portadas, los balcones, galerías ornamentos y el estilo al que pertenece la construcción.

- Contextual: Referido explícitamente al contexto, cómo el edificio se integra y guarda relación con el paisaje y si en conjunto crean una imagen.

Se puede notar que estos valores del Mincult son comparables con la concepción de Ballart y, al no existir una relación de valores que poseen los bienes culturales, se desarrolla la siguiente tabla de equivalencia teniendo en cuenta ambas definiciones para efectos de tener las variables para la valoración de las edificaciones (ver Tabla 1).

\section{Marco histórico}

\section{Bellavista a lo largo de la historia}

Para entender la razón de la construcción del distrito y su importancia, primero debemos conocer la historia previa que se vivió en el Callao y en Lima.

\section{Tiempos prehistóricos}

En el libro Historia del Callao: Pasado, Presente y Futuro, se sostiene que en tiempos prehistóricos, Bellavista fue un pueblo cazador y recolector en una primera fase; $y$ agricultor y pescador, en una segunda fase y que fue ampliamente estudiada por Max Uhle. "Los conchales de Bellavista revelaron al investigador, la existencia de una población que había hecho de la pesca su principal manera de alimentación" (Sánchez Olivencia, 1989, p. 155). Uhle habría encontrado capas de conchas mezcladas con cenizas, fragmentos de ollas y toscos implementos de hueso pertenecientes al Arcaico Cerámico.

En 1908, Max Uhle hizo referencia a los terrenos de Bellavista: 
El campo de descubrimientos más interesantes de los antiguos pescadores es sin duda Bellavista en el valle de Lima. La costa termina en un barranco de 17 metros en el cual rompen las olas con fuerza pero a 14 metros hay una capa blanca margosa de 4 centímetros de espesor, consecuencia de una inundación fluvial. Una antigua población fue arrasada por el brazo del río Rímac que por allí pasaba... (Sánchez, 1989, p. 155).

Según estudios geológicos, la desembocadura del río Rímac cambió de curso de la zona de La Perla hasta donde se halla en la actualidad como consecuencia de movimientos telúricos. Además, los textos indican que este pueblo de pescadores "...que fue arrasado por la salida catastrófica del río debió existir por la época en la cual el sur se florecía la civilización Nazca y Uhle hace referencia al período Intermedio Temprano (200 D.C.)" (Sánchez, 1989, p. 156).

\section{El puerto del Callao antes de la catástrofe de 1746 : La Colonia}

Fundada por los españoles en 1537, la ciudad del Callao nació de cara al mar; así, como puerto marítimo y centro poblado existe por necesidad geográfico-económico-políti$\mathrm{ca}$, por exigencias y mandato objetivos de las relaciones e intercambios con los demás países del mundo, para entrelazarse con los continentes en el campo del comercio, industria, negocios, ideas, instrucción, cultura, y toda la amplia y rica gama de posibilidades que trae consigo el contacto humano, el de las sociedades y el de los pueblos en pro de su desarrollo material y espiritual.

Por su cercanía a la capital peruana, durante el Virreinato del Perú era conocido, coloquialmente, como el Puerto de Lima o el Callao de Lima. Según el cronista indígena Felipe Guamán Poma de Ayala, ya desde esa época, el Callao era el puerto principal del Perú y de toda la costa occidental de Hispanoamérica.

El terremoto de 1746 fue una catástrofe de grandes magnitudes: la Lima amurallada de ese entonces, gobernada por por el Virrey Manso de Velasco, quedó en escombros. Al mismo tiempo, en el Callao se produjo un tsunami que arrasó con el puerto, dejando a las construcciones de la época sepultadas bajo el agua (ver Figura 3).

Después de la catástrofe de 1746: Fundación de Bellavista "La Nueva Capital del Callao"

La primera orden del Virrey, después de la catástrofe, fue "...la construcción de nuevas defensas en el Puerto, que lo pusieran al abrigo de enemigos futuros." (Arrús, 1904, p. 43).

Y por temor a que se repita el sismo, el Virrey Manso de Velasco decretó el 20 de Enero de 1747, después de un exhaustivo estudio, formar una población:

(...) en las tierras altas que están sobre el camino que va al Callao a la mano izquierda, donde las aguas no alcanzaron el sitio. Una vez seleccionado el lugar, fue comisionado el matemático Luis Godín, el mismo que diseñó el Real Felipe, para que delineara y fabricara casas, bodegas, rancherías, calles, plazas e iglesias, para la formación del pueblo, con el nombre de Bellavista. Su nombre se debe a ello: por su predominio ha merecido el nombre de Bellavista (Noblecilla, 2001, p. 132)

Y fue creada con el fin de ser la nueva capital del Puerto. A la par de la creación de Bellavista, se empezó la etapa inicial de la construcción del Real Felipe.

\section{Etapas del proceso de transformacón}

\section{Creación del distrito: Período del Virrey Manso de Velasco (1747 - 1767)}

"La construcción de Bellavista tuvo dificultades importantes que el Virrey Manso de Velasco supo vencer con decisión." (Quiroz, 2007, p. 150).

Bellavista, como las demás ciudades establecidas bajo el marco reformista de las Nuevas Poblaciones, buscó reproducir el ordenamiento físico de las primeras ciudades coloniales. 


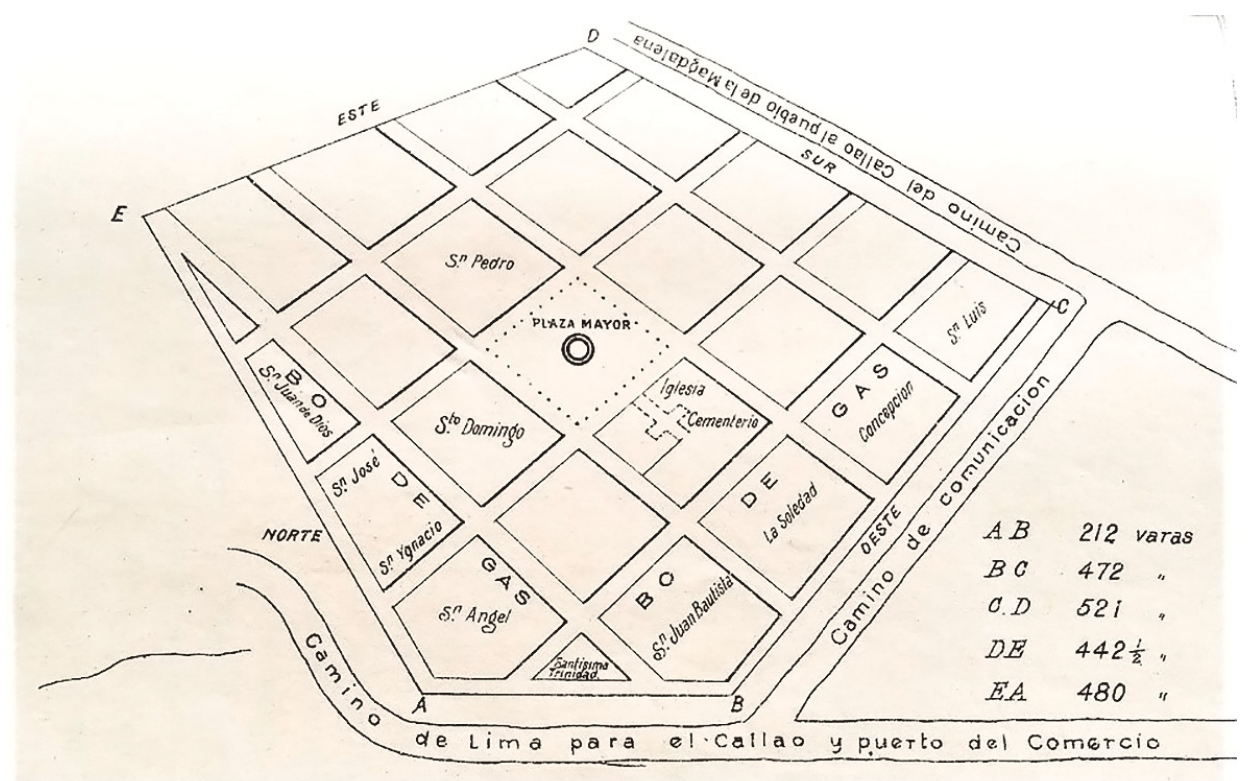

Figura 4. Plano del pueblo y bodegas de Bellavista, distante a un tercio de legua del Callao, a 17 varas de elevación sobre el nivel del mar, dedicado a los apóstoles Simón y Judas y a la iglesia al Santo rey D. Fernando con la distribución de sus calles, bodegas y plazas regulares, de cien varas en cuadro". Recuperado del Archivo General de Indias. Est. 115 Coy. 3. Log 10, 2007.

Su trazado repitió algunos rasgos del urbanismo del siglo XVI de las ciudades hispanoamericanas"(...) un tipo nítidamente definido por su estructura física en cuadrícula, sin acentos ni contrastes y con un único elemento diferenciado al centro: la plaza central" (Ríos, 2014, p. 43), y los mismos principios del urbanismo barroco de la ciudad de Lima (ver Figura 4).

Por lo tanto, el trazado del Núcleo Histórico tuvo las siguientes características:

1) La adopción de una trama reticular y con perímetro poligonal.

2) "algunos trazados de este período reflejan preocupaciones de tipo formalista y simbólico, destinadas a proyectar una imagen de la ciudad superior a su verdadera consistencia... responden a conceptos teóricos de defensa modernos" (Mattos-Cárdenas, 2004, p. 89).

3) La organización espacial a partir de una plaza regular central, "...espacio público principal y corazón de la urbe, el núcleo estructural básico desde donde se genera y articula la ciudad: la plaza mayor, centro geométrico, vital y simbólico". (Quevedo, 2016, p. 13). En esta Plaza Mayor se ubicó la Iglesia Parroquial y demás edificios públicos.

En las ciudades hispanoamericanas, la Plaza Mayor tiene una gran importancia puesto que al ser el elemento estructural básico desde donde se genera y se organiza el pueblo, termina siendo "el punto en el que confluye la vida ciudadana, lugar de encuentro para todas las funciones sociales, oficiales o de diversión y esparcimiento" (Ministerio de Educación, Cultura y Deporte, 2001, p. 25).

El trazado del Nuevo Callao impuesto por el Virrey Manso propugnaba así una visión ilustrada, laica y racional, donde se limitaba la participación de las órdenes religiosas y se privilegiaba un ordenamiento matemático, en base a los principios de la arquitectura militar. De acuerdo con esta visión, el Virrey prohibió expresamente la construcción de monasterios por parte del clero regular, a la manera de Bellavista. Se argumentaba 


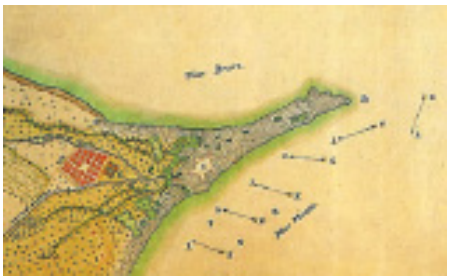

Figura 5. Plano de Bellavista en relación con el Callao a mediados del siglo XVIII. Recuperado de http://www. esteticas.unam.mx/revista_imagenes/rastros/ras_isaenz01.html, 2016.

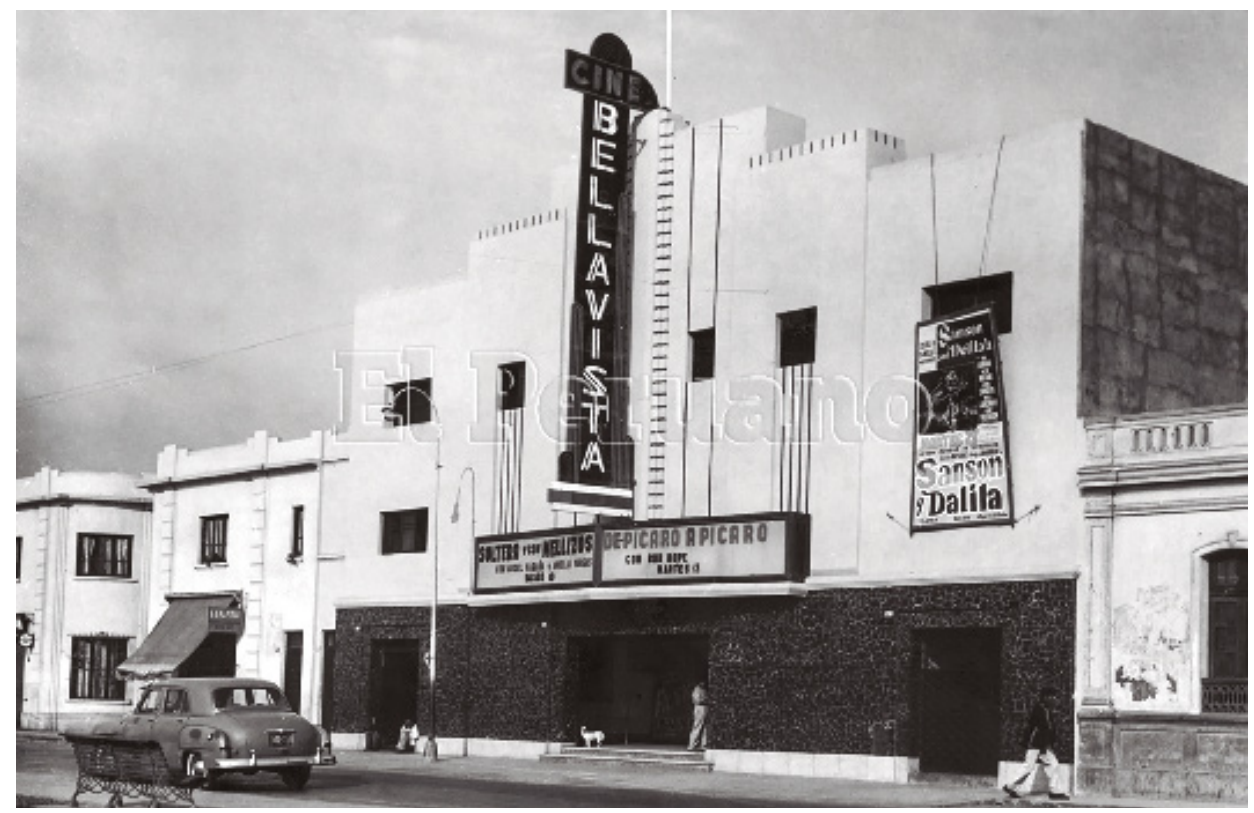

Figura 6. Antiguo cine Bellavista en el año 1951. Recuperado de Archivo Histórico del diario El Peruano, 1951.

que las órdenes mendicantes, "además de constituir un gasto para el erario, dilatarían las obras de fortificación, constituyéndose en un estorbo para la defensa" (Quiroz 2007, p. 150) (ver Figura 5).

De esta manera, la fundación del pueblo de Bellavista fue para proveer a la fortaleza del Callao y como vivienda para comerciantes, gente de mar y sus respectivas familias, y bajo esta mirada se determinó que la población civil se confinara en este lugar. En el libro Callao en la época del Coloniaje se menciona una frase de Luis Godín: "En la cabecera se construirán las bodegas y demás casas para el servicio de la marina" (Arrús, 1904, p. 68). El pueblo tenía calles anchas y rectas con una plaza cuadrada en el centro. Uno de los extremos de la plaza estaba destinado a la iglesia parroquial y el cementerio; en el lado opuesto,

(...) el cabildo habilitó en 1776 la casa del conde de San Javier, para ser usada en el recibimiento del nuevo virrey Manuel de Guirior. Probablemente esta sea la casa que fue usada y conocida luego como el palacio de los virreyes. El resto de la población consistía en bodegas del comercio. (Quiroz, 2007, p. 154).

Después de casi dos siglos, el llamado Palacio de los virreyes se convirtió en símbolo popular: en el primer cine del Callao. Sin embargo, dicha estructura se encuentra abandonada en la actualidad (ver Figura 6).

\section{Florecimiento del distrito: Período del Virrey Manuel de Amat (1761- 1776)}

Durante el gobierno del virrey Amat, al consolidarse Bellavista como pueblo, aumentó su población, y dio origen a la construcción de oficinas y almacenes fiscales. Pero, también se construyó el Real Hospital de Bellavista para marineros y guarnición militar del puerto del Callao. En el mismo terreno, funciona actualmente el hospital Daniel Alcides Carrión.

\section{Fracaso como nueva capital del Primer Puerto (1777)}

En el Callao, el impacto del sismo fue tal que no hubo lugar para "cirugías urbanas" y mas bien se levantó una nueva ciudad militar sobre los rastros y vestigios de una antigua urbe mercantil y portuaria. Dadas las condiciones del puerto, la visión utópica de virreyes, marinos y funcionarios de construir una urbe segura y articulada con el circui- 
to mercantil no tuvo muchos opositores. Sin embargo, con la creación de Bellavista, la reubicación del Callao fue sólo un proyecto parcial y momentáneamente exitoso. En términos prácticos, siguiendo un patrón de larga data, muy pronto se inició un proceso de reocupación del entorno marítimo y a principios del siglo XIX, en buena medida, había recuperado sus características anteriores al sismo de 1746:

Posteriormente, fueron permitiéndose construcciones sencillas en el Callao, bajo la condición de ser destruidas sin responsabilidad(...) Por eso se explica el desorden con que se levantaron las primeras casas, desorden que se conserva hoy mismo en la parte antigua de su población. (Arrús, 1904, p. 50).

Debido a este fenómeno, la población de Bellavista disminuyó y dejó de ser la nueva capital del puerto, iniciándose así un proceso de abandono y deterioro de los componentes de su núcleo histórico (ver Figura 7).

\section{Período de invasiones: Transformaciones en la trama y en la arquitectura}

Al no existir una reglamentación por parte de las autoridades y carecer de un plan, sumado esto al crecimiento de la población en los últimos años, han venido ocurriendo ciertos cambios en la trama del Núcleo Histórico de Bellavista, en su arquitectura y escala.

En cuanto a la trama, esta transformación se ha dado en menor escala, ya que gran parte sigue intacta, sin embargo, en la zona Este se dio una transformación total debido a las invasiones, donde habita una población de bajos recursos; además se unen dos manzanas en la zona sur para crear el estadio Telmo Carbajo, cuya fachada fue declarada Bien integrante del Patrimonio Cultural de la Nación por el Instituto Nacional de Cultura (INC) en 1990, y en la zona Nor-Este, se unen dos manzanas para la construcción del histórico Club de Tiro de Bellavista (ver Figura 8).

En cuanto a su arquitectura, en el Núcleo Histórico de Bellavista se pueden ver los distintos periodos que ha vivido: colonial, republicano, moderno y "chicha". Al no haber leyes que protejan la arquitectura de época, la de los primeros años de su fundación, estas casonas antiguas poco a poco han ido desapareciendo para dar paso a una arquitectura que no guarda ninguna relación con las casonas que aún siguen en pie, es decir, imagen urbana degradada de esta área histórica.

\section{Cambio de densidades en los últimos años (2012 - a ctualidad)}

Una de las particularidades de este Núcleo Histórico era el perfil que mantenía. No obstante, por falta de una gestión eficiente y por el desinterés de sus autoridades en proteger su patrimonio, se están aceptando demoliciones de casas antiguas así como remodelaciones que no se respetan las formas arquitectónicas de la época (ver Figura 9).

Otro factor que influye en la transformación de la arquitectura son los procesos de sucesión que ocurren desde hace muchos años, donde los nuevos dueños le dan otro tipo de uso a las viviendas convirtiéndolas en tiendas de comercio o en funerarias, como pasa con algunas viviendas tipo rancho frente a la plaza Isabel La Católica.

La construcción de estos nuevos edificios son autorizados por la misma Municipalidad Distrital, por ejemplo, la autorización de la construcción de un edificio de oficinas en un área totalmente residencial o el permiso para hacer una construcción multifamiliar de 9 pisos frente a la Plaza Principal que rompe con la escala urbana de la zona y compite con la Parroquia, a pesar de que el Plan de Desarrollo Urbano de la Provincia Constitucional de Callao indica que en esta zona la altura máxima permitida es solo hasta 5 pisos.

Si el boom inmobiliario aún no se da en todo su esplendor dentro de esta área histórica de Bellavista, es por las dificultades que hay para acceder al transporte público. Sin embargo, con la próxima apertura de la nueva vía de la Costa Verde que irá hasta La Punta, estos procesos de densificación pueden llegar con más fuerza a esta zona.

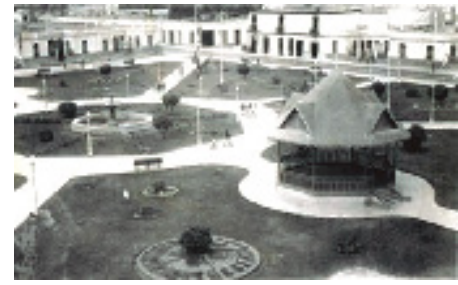

Figura 07. Panorámica de 1930 con la Pileta ornamental histórica de Bellavista instalada por el Presidente José Balta (1869) y la antigua glorieta de la Plaza, retirada desde hace varios. En archivo online La Premiere Peruanacas, 2016.

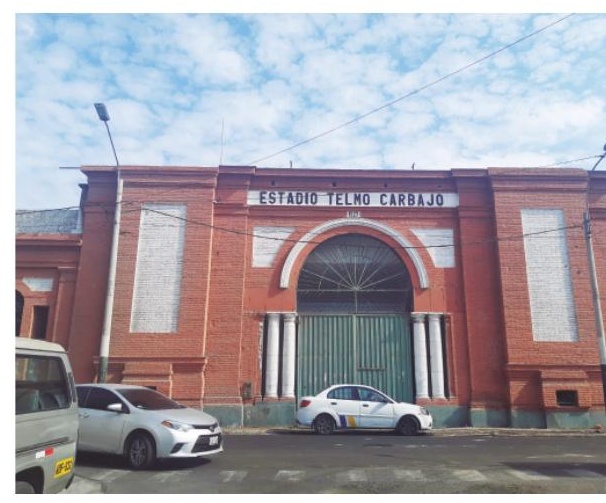

Figura 08. Fachada del Estadio Telmo Carbajo. Archivo fotográfico de la autora, 2019. 
devenir Vol. 7, N¹3, ENERO - JUNIO 2020, PP. 31-58 - ESTUDIOS I ISSN 2312-7562 | E-ISSN 2616-4949

UNIVERSIDAD NACIONAL DE INGENIERÍA, LIMA

doi: https://doi.org/10.21754/devenir.v7i13.925

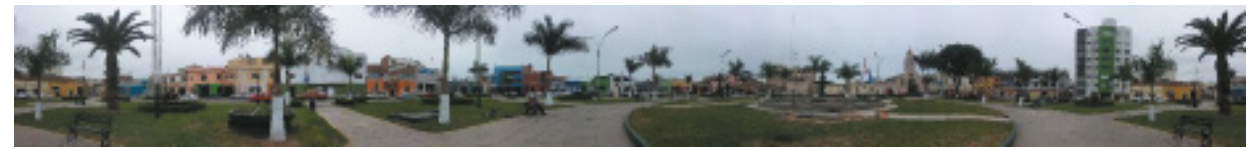

Figura 09. Escala del Casco Histórico del distrito de Bellavista y ruptura del perfil urbano por el multifamiliar edificado frente a la Plaza Principal. Archivo fotográfico de la autora, 2016.

\section{Marco histórico arquitectónico}

Según la información recopilada, el inventario realizado y la observación crítica basada en mi vivencia como habitante de la zona de estudio, se pueden determinar cuatro periodos de desarrollo de la Arquitectura en Bellavista (ver Figura 10):

\section{Diseño metodológico}

Para que el Núcleo Histórico de Bellavista sea declarado Zona Monumental, hay que hacer primero una catalogación e inventario de la arquitectura y ambientes urbanos en la zona:

\section{Inventario UNI-FORD}

El Inventario de Patrimonio Edificado más completo sobre la ciudad de Lima fue el Inventario del Patrimonio Monumental Inmueble - Lima: Valles de Chillón, Rímac y Lurín, realizado gracias al convenio entre la Facultad de Arquitectura, Urbanismo y Artes de la Universidad Nacional de Ingeniería y la Fundación FORD. El inventario organiza el Patrimonio Monumental Inmueble en 4 épocas: Prehispánica (424 Monumentos), Virreinal (215 Monumentos), Republicana (239 Monumentos) y Contemporánea (183 Monumentos). El número total de monumentos considerados en el Inventario es de 1,061 en Lima.

Cada monumento está presentado con una ficha que incluye:

- Identificación: Código del monumento, existencia actual, tipo genérico, tipo específico, Nombre del monumento, ubicación geográfica, ubicación política, datos cartográficos y fotográficos, y accesibilidad.

- Descripción del monumento: Área del terreno, área construida, área techada, filiación cultural, filiación cronológica, descripción, mobiliario y/o elementos.

- Datos históricos: Autor(es), comitente, etapas de construcción (años), intervenciones, tipos de intervenciones y años, bibliografía e inventario.

- Datos técnicos: Estado de conservación, sistema estructural, materiales predominantes, instalaciones, amenaza de destrucción, uso actual, tugurizado, propietario, saneamiento legal, declarado monumento, dispositivo legal, fecha dispositivo.

- Observaciones.

- Otros: Ejecución, revisión, visación y fecha.

Asimismo, se incluye una foto del Monumento, un plano de ubicación, y planta de distribución. Es importante señalar que "la selección de los edificios, ambientes, conjuntos, etc. estuvo supeditada a distintos criterios. Cabe señalar, sin embargo, que se han incluido indistintamente Monumentos ya declarados en la Legislación como sujetos de preservación y otros que se propone como tales" (Universidad Nacional de Ingeniería - Facultad de Arquitectura, Urbanismo y Artes - Fundación FORD, 1994).

El inventario consta de 6 tomos. El primer tomo corresponde al reporte estadístico de la información obtenida, y los otros tomos corresponden a las épocas estudiadas: Prehispánica ( 2 tomos), Virreinal (1 tomo), Republicana (1 tomo), Contemporánea (1 tomo). 


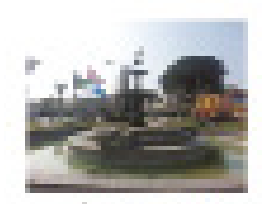

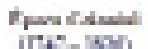
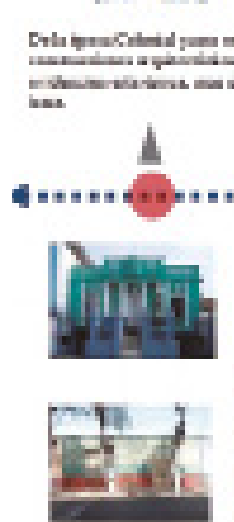

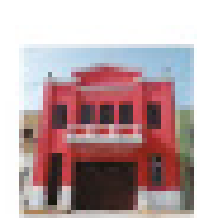

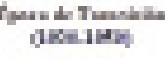

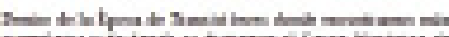

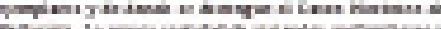
-

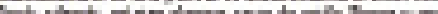

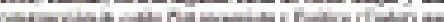

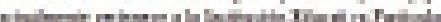
Tra

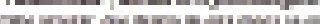

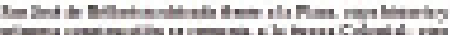

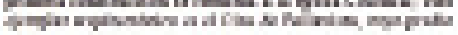
hy

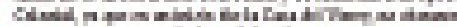

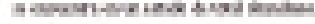
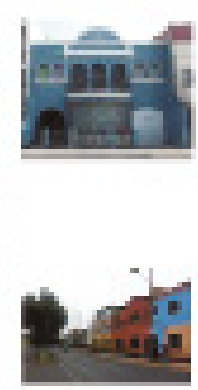

1
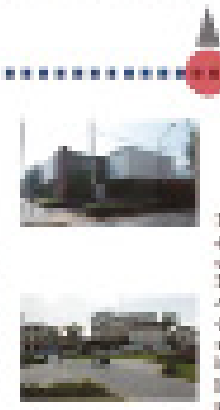

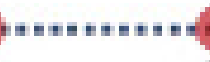

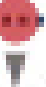

Tнн Juln

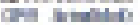

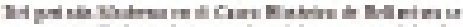

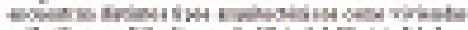

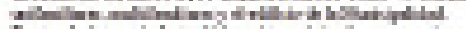

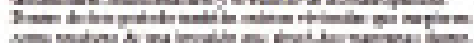

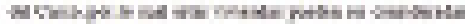

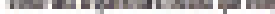

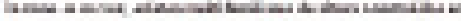

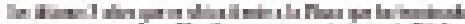

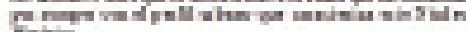
hats.

Figura 10. Línea del tiempo que muestra las épocas en las que se desarrolló la arquitectura del Núcleo Histórico de Bellavista. Elaboración propia sobre la base de trabajo de campo, 2016.

\section{Procedimiento para la Declaración de un Monumento Nacional y requisitos mínimos para presentar una solicitud de declaración en Perú}

Según el Ministerio de Cultura, la Dirección Desconcentrada de Cultura del Callao otorga un documento en donde se exponen los procedimientos para Declaratorias en el cual se expone que:

La Declaración de bien integrante del Patrimonio Cultural de la Nación puede ser de oficio o a solicitud de parte. Si es a solicitud de parte no está establecido los requisitos, sin embargo, de la práctica se obtiene que es necesaria la siguiente información:

- Propietario actual debidamente acreditado.

- Copia de la Partida Registral completa.

- Investigación histórica del bien que postula.

- Plano de distribución impreso y en Autocad.

- Plano de ubicación.

- Fotografías antiguas.

- Fotografías actuales interiores y exteriores.

- Identificación de valores culturales, importancia y significado del inmueble que amerite su declaratoria. 


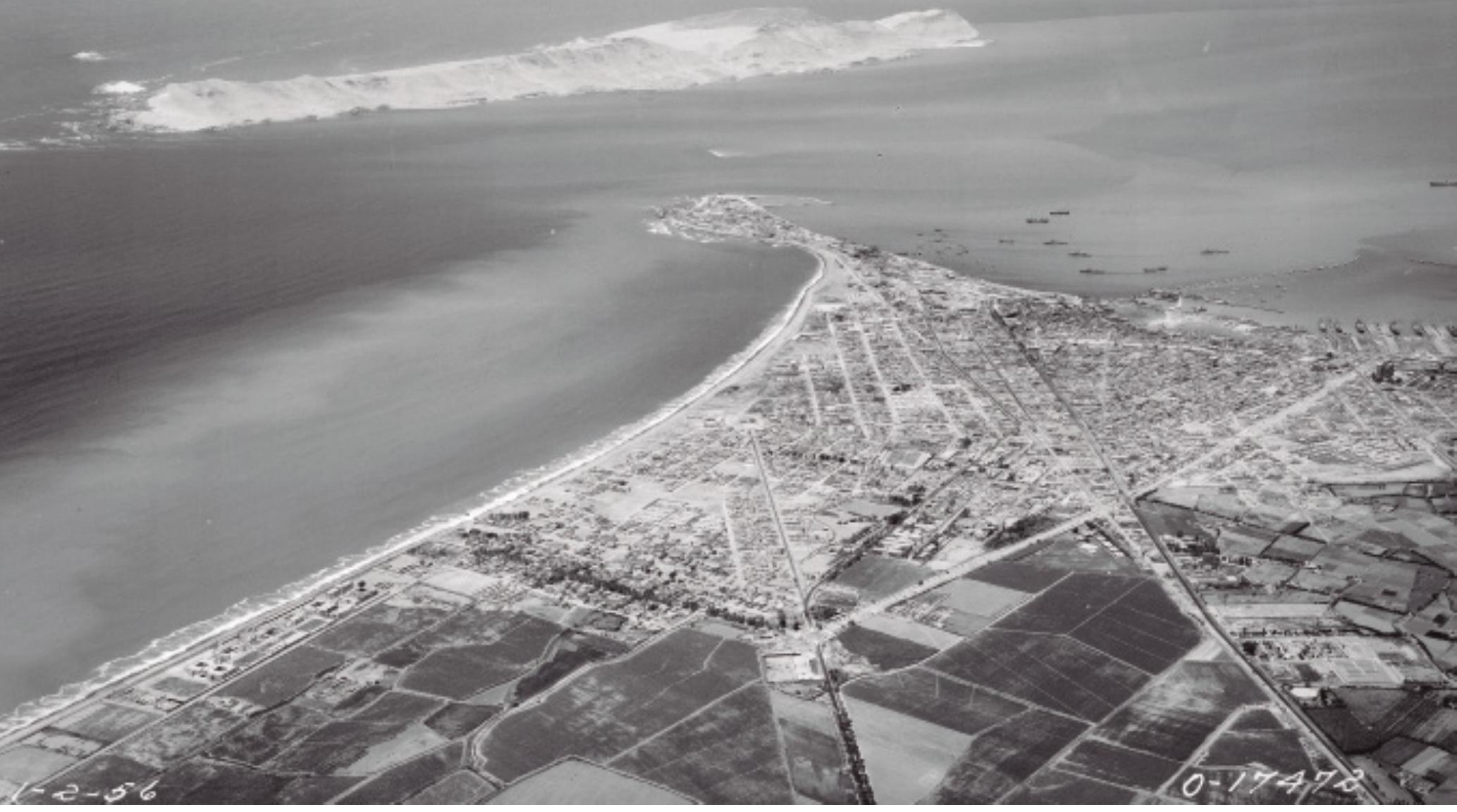

Figura 11. Aerofotografía donde se observa el emplazamiento de Bellavista. Archivo del Servicio Aerofotográfico Nacional, 1956.

\section{Resultados}

\section{El paisaje y la influencia de la topografía en el emplazamiento del distrito.}

La topografía jugó un rol muy importante para el emplazamiento de Bellavista. Entre el borde marino y el Núcleo Histórico de Bellavista existe una distancia de 600 metros por el sur y 2 kilómetros y medio por el oeste aproximadamente, con una pendiente suave que alcanza los 17 m.s.n.m. que posteriormente se convierte en un terreno llano donde se establece Bellavista.

Entonces Bellavista quedó sobre un terreno a una altura de 17 m.s.n.m. en donde pudiera estar protegido de otro eventual maremoto, cuyas calles reticulares se encuentran orientadas en los ejes Noreste-Suroeste (NE-SO) y Sureste-Noroeste (SE-NO), al igual que el damero de Lima, emplazadas entre los dos ejes principales de esa época: El Antiguo Camino hacia Lima y el Camino hacia Maranga. Esto generaba la inclusión del paisaje marino como protagonista (ver Figura 11).

Por su ubicación privilegiada que permite ver la bahía desde sus calles, recibió el nombre de Bellavista. Sin duda, el paisaje es un valor agregado que posee el Núcleo Histórico de Bellavista por ser único en el Callao. Un buen ejemplo es la avenida Bolognesi, poblada de sauces y cuya orientación hacia el océano nos permite gozar de una vista particular (ver Figura 12). 


\section{Morfología urbana del área de estudio}

Para poder analizar la morfología urbana del Núcleo Histórico de Bellavista, primero debemos tomar como referencia las siguientes variables de la Forma Urbana que se encuentra en la publicación de Alejandra Sgroi (2009, pp. 06-14):

\section{Traza}

Esquema básico determinado por la red vial (calles) y los lotes que delimita. Puede ser:

- Cuadricular: Crecimiento simétrico a partir de dameros perfectos.

- Irregular: Se presenta cuando se rebasa la forma original con crecimientos asimétricos que amenazan o desvirtúan su orden básico.

- Irregular Radial o Concéntrica: utilizado cuando se organiza la ciudad en torno a un punto central, las calles se disponen en forma de círculos concéntricos. A partir del punto central de la ciudad se proyectan las calles que la comunican con el exterior o periferia.

- Barroca: Derivada del damero pero enriquecida por la tradición de los trazados ideales del urbanismo barroco que genera plazuelas, rotondas y otros elementos que rompen con la uniformidad de la cuadrícula.

\section{Manzana}

- Cuadrada: Reproduce análogamente la manzana típica de las ciudades de la conquista.

- Rectangular: En distintas dimensiones, brinda una mejor proporción en los lotes y en algunos casos racionalidad en la configuración de la red circulatoria, aunque en otros casos responde a una cuestión formal.

- Triangular: Originado por la irrupción de diagonales sobre la trama reticulada. También origina manzanas trapezoidales con dificultades en el fraccionamiento parcelario.

\section{Parcela}

División de terrenos en dos o más nuevas parcelas independientes (ver Figura 13).

- Tipo X: Modelo universal de parcelamiento de la manzana cuadrada. Adoptado a fin de lograr la mayor cantidad de fracciones con acceso directo a la vía pública.

-Tipo H: Aplicado en manzanas cuadradas pero especialmente en rectangulares con el fin de lograr lotes no muy dispares.

- Tipo Y: La manzana triangular tiene la dificultad de no poder ser parcelada racionalmente. De ella surgen lotes triangulares, cuadriláteros, de todo tipo y polígonos más complicados.

-Tipo Curvilíneo.- Se trata de una manzana irregular o curvilínea que produce un tipo diferente de parcelación, donde se dificulta su mesura y la regularidad de sus lotes.

\section{Textura}

Es la estructura que define las formas de la variante relación entre llenos y vacíos. Es la relación entre volúmenes edificados y los espacios abiertos, es decir permite percibir la mayor o menor compacidad y el suelo libre. La textura puede o no revelar densidades, ya que solo se trata de la compactación de la superficie y no toma en cuenta el uso de los edificios.

- Cerrada (- vacíos | + llenos): La manzana alcanza su completamiento y los huecos de los lotes son sustituidos por construcciones, dando como resultado una trama cerrada que solo respira a través de la red de calles.

- Abierta (+ vacíos | - Ilenos): Se da por un parcelamiento holgado y bajo porcentaje edificado, o por encontrarse el tejido urbano en un estado intermedio en el proceso de compactación.

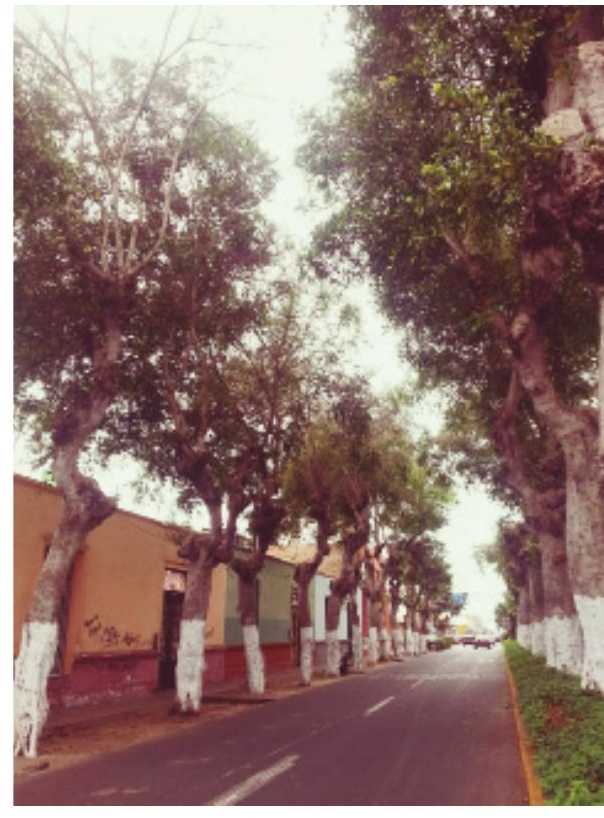

Figuras 12. Avenida Bolognesi, como senda principal en la época del pueblo de Bellavista al conectar con el antiguo camino hacia Lima (actualmente conecta con la Av. Colonial. Archivo fotográfico personal, 2016.

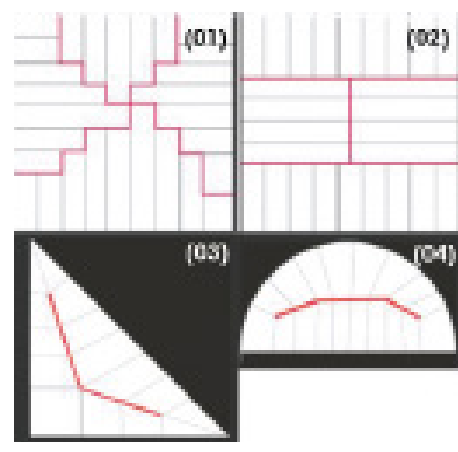

Figura 13. Gráficos de los tipos de Parcelas: (1) Tipo X, (2) Tipo H, (3) Tipo Y, (4) Tipo Curvilíneo. Sgroi, 2009. 
devenir Vol. 7, N¹3, ENERO - JUNIO 2020, PP. 31-58 - ESTUDIOS I ISSN 2312-7562 | E-ISSN 2616-4949

UNIVERSIDAD NACIONAL DE INGENIERÍA, LIMA

doi: https://doi.org/10.21754/devenir.v7i13.925

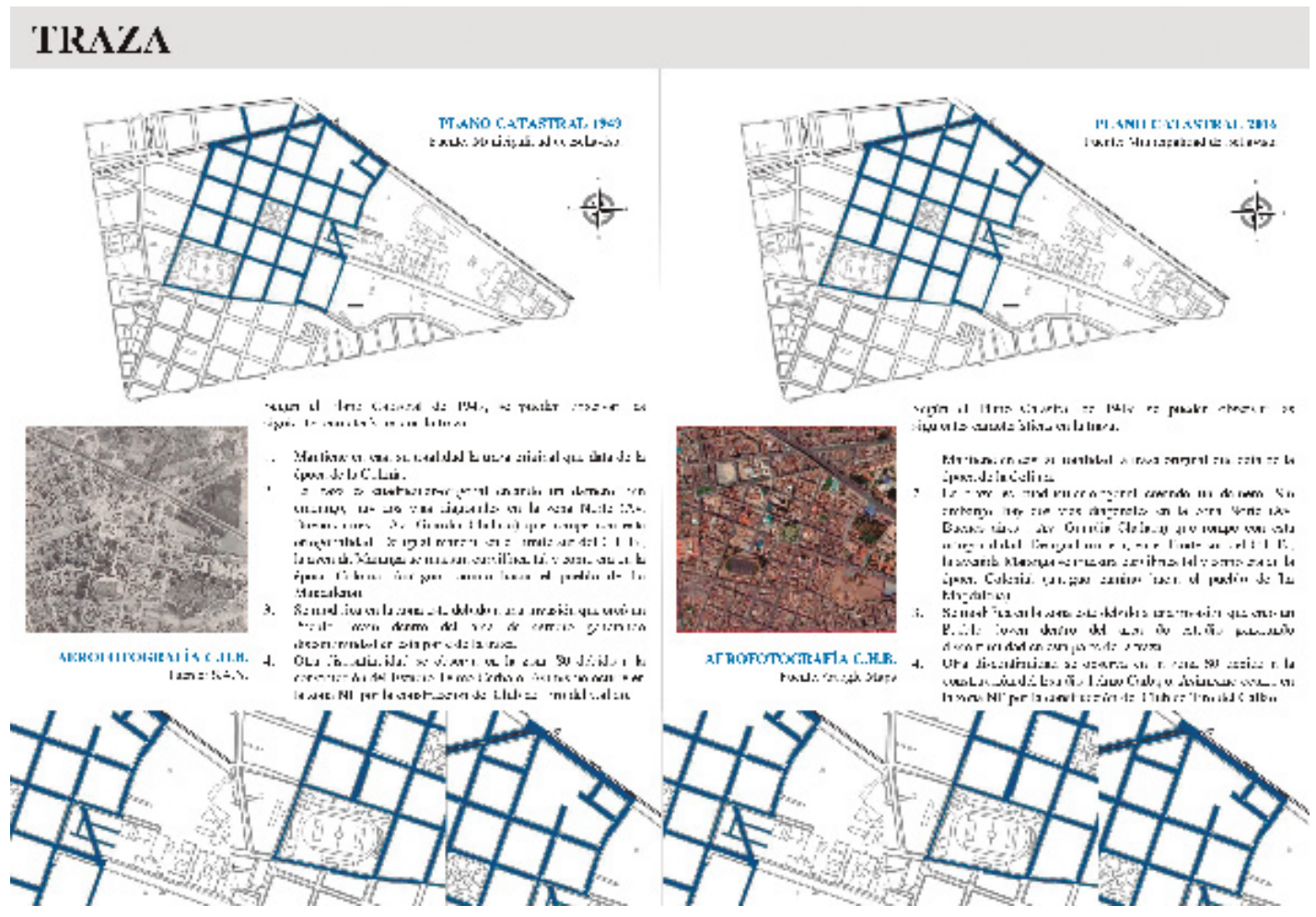

Figura 14. Comparación de planos del estudio de la traza del Núcleo Histórico de Bellavista en base al Plano Catastral de 1949 versus el del 2016. Elaboración propia, 2016.

\section{MLYZLYA}
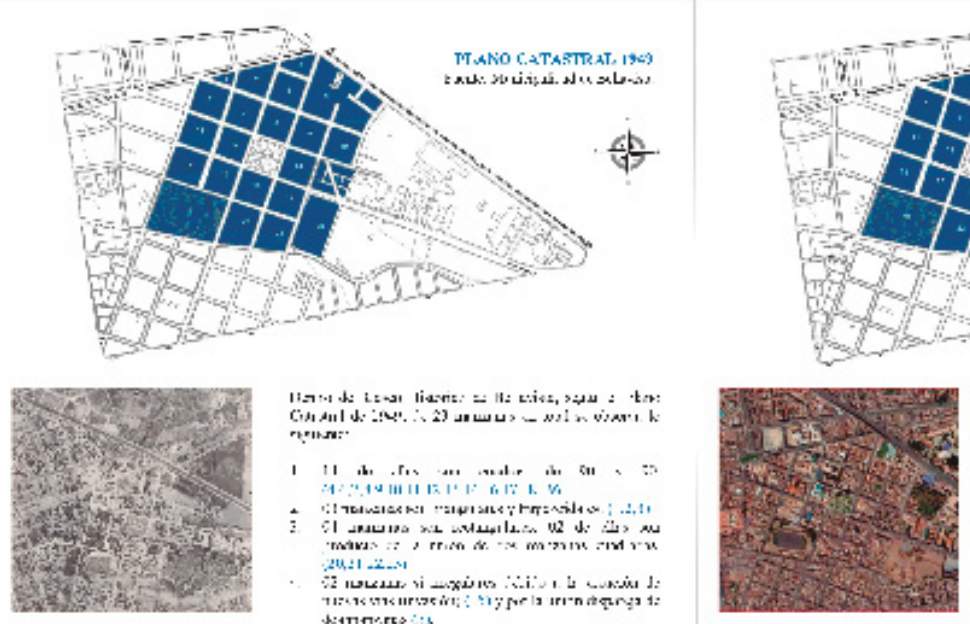

Delo

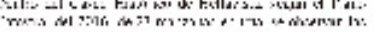

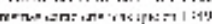

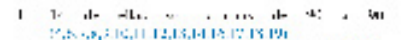

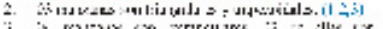

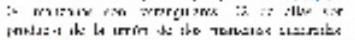

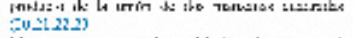

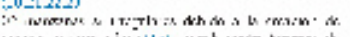

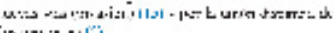

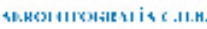
ditnerses:

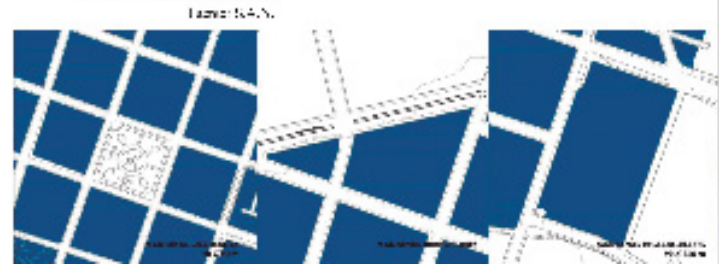

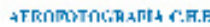
in aloters

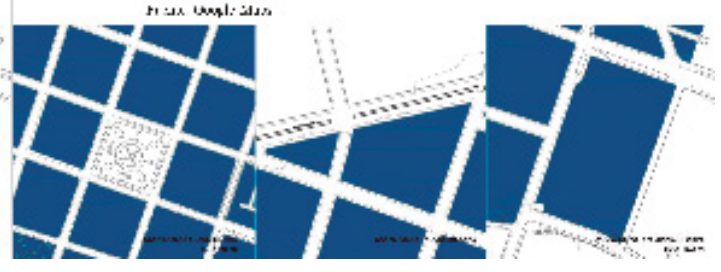

Figura 15. Comparación de planos del estudio de manzanas del Núcleo Histórico de Bellavista en base al Plano Catastral de 1949 versus el del 2016. Elaboración propia, 2016. 


\section{PARCELACIÓN}
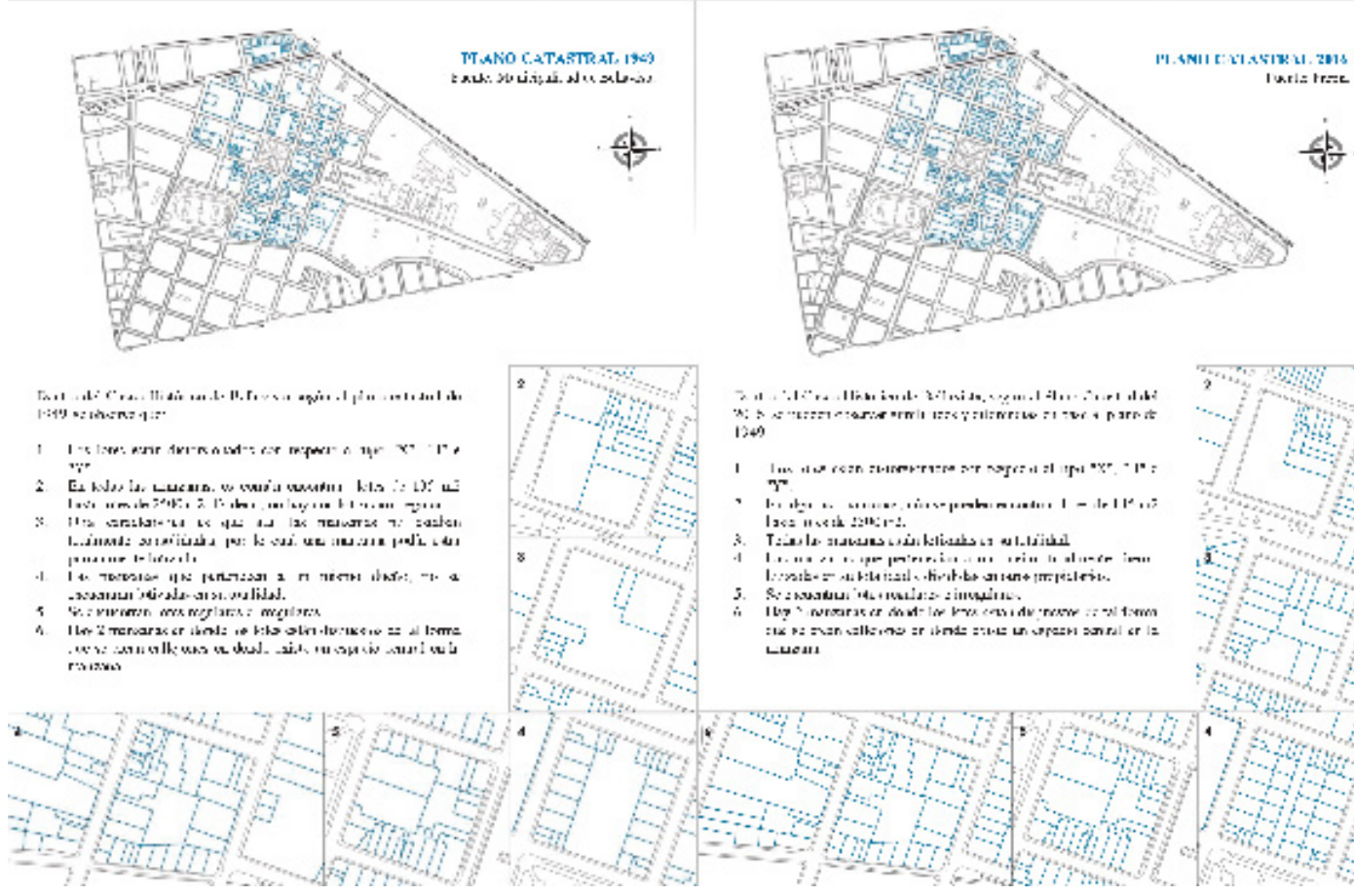

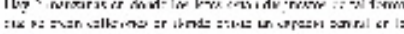

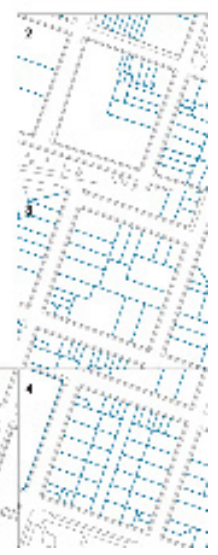

Figura 16. Comparación de planos del estudio de la Parcelación del Núcleo Histórico de Bellavista en base al Plano Catastral de 1949 versus el del 2016. Elaboración propia, 2016.

\section{TEXILRA Y GIRANO}
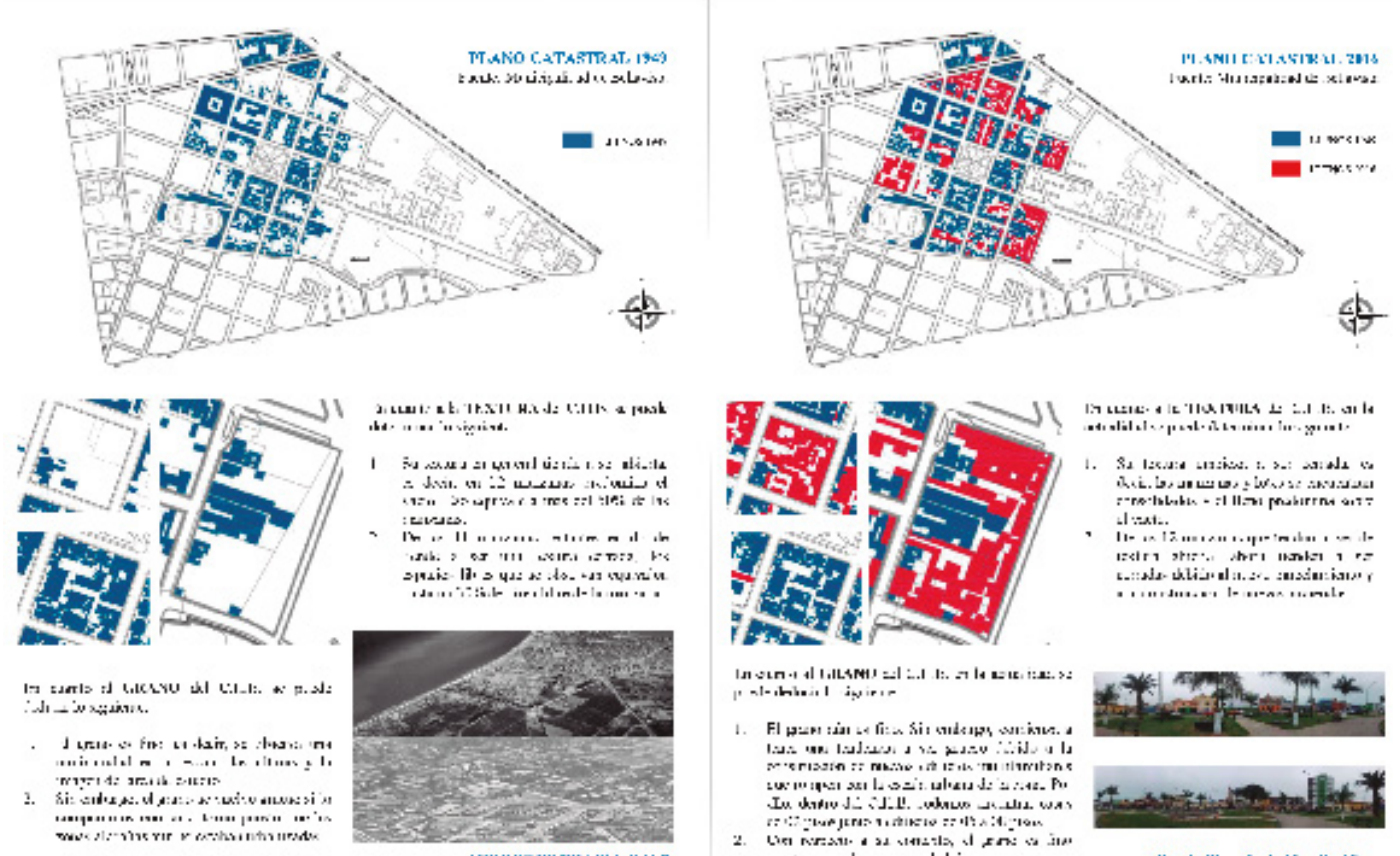

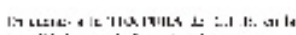

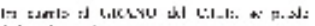

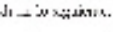

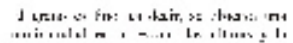
- $4:$ נr.

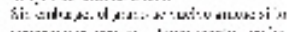

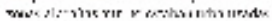

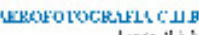

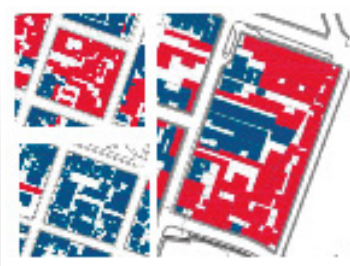

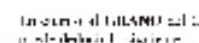

FI ta:m :

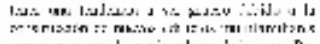

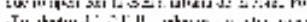

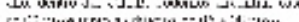

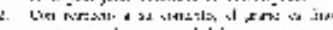

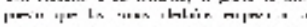

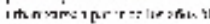

(at.

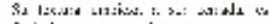

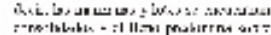

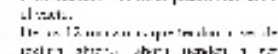

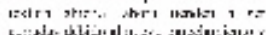

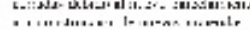
Ianie s.t.

Figura 17. Comparación de planos del estudio de Textura y Grano del Núcleo Histórico de Bellavista en base al Plano Catastral de 1949 versus el del 2016. Elaboración propia, 2016. 
devenir Vol. 7, N¹3, ENERO - JUNIO 2020, PP. 31-58 - ESTUDIOS I ISSN 2312-7562 | E-ISSN 2616-4949

UNIVERSIDAD NACIONAL DE INGENIERÍA, LIMA

doi: https://doi.org/10.21754/devenir.v7i13.925

Grano

Relacionado con la textura en cuanto a su homogeneidad y heterogeneidad.

- Grano Fino: Logrado por la presencia de tipos de edificación uniformes basados en la repetición de unidades semejantes.

- Grano Grueso: Cuando la textura urbana está constituida por elementos resaltantes, en los que se juntan altas y bajas densidades, es decir, cuando aparecen elementos de distinta escala.

En cuanto al área de estudio, la traza urbana quedó establecida al configurarse la trama ortogonal de Godín, teniendo solo ligeras modificaciones en la actualidad.

En la última etapa de la historia urbana de Bellavista, la morfología del distrito se presenta de la siguiente manera (ver Figuras $14,15,16$ y 17 ):

En cuanto a su escala, la mayoría de edificaciones son de densidad baja-media por lo que el promedio de viviendas que existe son de dos a tres pisos.

Alrededor de la Plaza Isabel La Católica, el espacio libre más importante, se encuentran los hitos más importantes del Casco Histórico: La Parroquia San José, la Municipalidad, el antiguo cine de Bellavista, y la pileta que se encuentra al centro de la plaza que es considerada monumento histórico del Callao.

\section{El núcleo histórico de Bellavista en la perspectiva de su declaración como Bien integrante del Patrimonio Cultural de la Nación: Identificación del universo y elección de la muestra}

\section{Delimitación del Núcleo Histórico de Bellavista}

Para este trabajo de investigación, parto de la premisa de la delimitación de Godín, quien originalmente planteó una traza con 25 manzanas con los límites descritos, según las calles actuales, líneas abajo (ver Figura 18).

Sin embargo, debido a las transformaciones de los últimos años, es necesaria una nueva propuesta para la delimitación del Núcleo Histórico de Bellavista, que hoy contaría con 18 manzanas respecto a su plano fundacional. En el esquema se puede observar que la zona Este es la que ha sufrido mayores cambios de los límites debido a las invasiones que se dieron en las últimas décadas. Tanto han sido afectadas la trama original y la arquitectura de esta zona que ya no puede formar parte del Núcleo Histórico en la nueva delimitación propuesta.

\section{Descripción de los tipos arquitectónicos}

Luego de realizar la observación crítica en el Núcleo Histórico de Bellavista, se realizó una catalogación que sirvió para identificar a las construcciones con posibilidades para la declaración de Patrimonio.

Dentro del área de estudio se encontraron varios tipos como viviendas multifamiliares, unifamiliares dentro de las cuales se encuentran ranchos tipo $\mathrm{L}$, tipo $\mathrm{H}$, tipo Zócalo, tipo Mirador, de la época Republicana y de la época de Transición, de estilo Art-Decó, así como también viviendas pareadas y en serie que en una época pertenecían a una sola manzana; sin embargo, con los cambios de propietarios, estas viviendas se fueron alterando tanto en fachada como en distribución interna.

A su vez también se encuentran tipos arquitectónicos como la iglesia, el cine, la municipalidad todos ellos ubicados frente al único ambiente urbano del Núcleo Histórico: la Plaza Isabel La Católica, la cual es considerada como la primera Plaza de Armas que tuvo el Callao y que pertenece a la época Colonial (ver Tabla 2). 


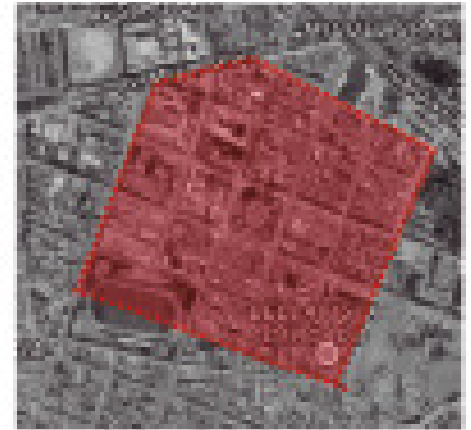

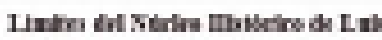

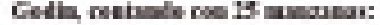

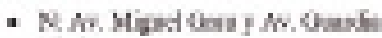
Din

+ Brimina:

- Ethanih

- Defintipir

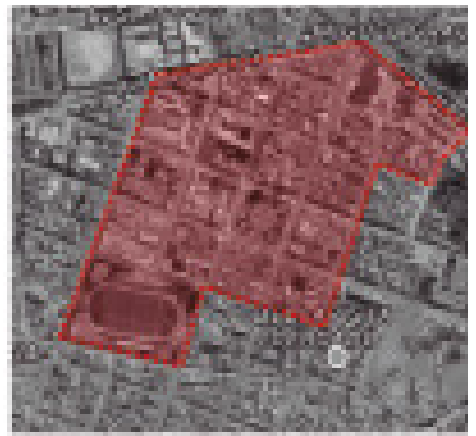

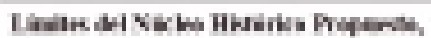

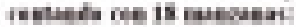

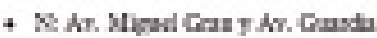
바뇨

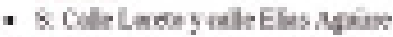

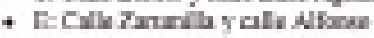
Lirn:

- OrCallapingr

Figura 18. Planos de propuesta para la nueva delimitación del Centro Histórico de Bellavista. Elaboración propia, 2016.

\begin{tabular}{lll}
$\begin{array}{l}\text { Tabla 2. Cuadro de los tipos arquitectónicos existentes en el Núcleo } \\
\text { Histórico de Bellavista. }\end{array}$ & \multicolumn{1}{c}{ Tipo } & \multicolumn{1}{c}{ Tipo específico } \\
\hline \multicolumn{1}{c}{ Época } & \multicolumn{1}{c}{ Tip. Doméstica } & $\begin{array}{l}\text { Unifamiliar (Casas Rancho) } \\
\text { Multifamiliar }\end{array}$ \\
\hline Republicana & Arq. Industrial & Bodega \\
\hline Transición & Arq. Doméstica & Unifamiliar \\
& & Multifamiliar \\
& Arq. Civil Pública & Estadio \\
& Arq. Religiosa & Iglesia \\
\hline Moderna & Arq. Doméstica & Unifamiliar \\
& & Multifamiliar \\
& Arq. Civil Pública & Municipalidad \\
& & Cine \\
\hline Elaborado propia, 2016. &
\end{tabular}

\section{Descripción de ambientes urbano-monumentales}

A nivel urbano, se presentan los ambientes urbano-monumentales correspondientes para una posible declaración de Monumentos del Núcleo Histórico de Bellavista:
a) La Plaza Isabel La Católica
b) El Jr. Bolognesi
c) El Jr. Los Heros
d) El Jr. Grau 
devenir Vol. 7, N¹3, ENERO - JUNIO 2020, PP. 31-58 - ESTUDIOS I ISSN 2312-7562 | E-ISSN 2616-4949

UNIVERSIDAD NACIONAL DE INGENIERÍA, LIMA

doi: https://doi.org/10.21754/devenir.v7i13.925

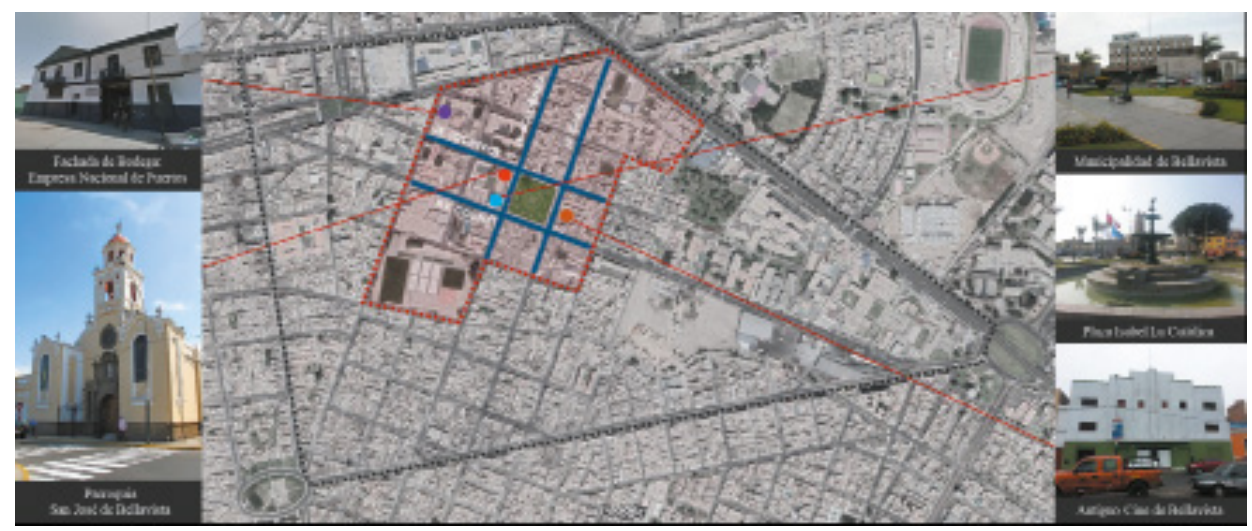

Figura 19. Fotografía aerea del Núcleo Histórico de Bellavista donde se muestran los principales hitos y ambientes urbano-monumentales de la zona propuestos para la declaración de monumentos. Elaboración propia, 2019.

\section{e) La Av. Colina}

A nivel arquitectónico, dentro del Casco Histórico de Bellavista se presenta el siguiente número de edificaciones que pueden ser declaradas monumentos (ver Figura 19):

a) Arquitectura religiosa: 01 edificación

Parroquia San José de Bellavista (Periodo Independencia - Época Colonial)

b) Arquitectura industrial: 01 edificación

Fachada de bodega. Actualmente: Empresa Nacional de Puertos (Época Republicana)

c) Arquitectura civil: 02 edificaciones

Municipalidad de Bellavista (periodo Moderno) y Estadio Telmo Carbajo (periodo de Transición)

d) Arquitectura doméstica: 104 edificaciones

Por lo cual se desarrolla una matriz de clasificación para la elección de la muestra:

\section{Elaboración de matriz de clasificación}

Para poder realizar las fichas de inventario, primero se realizó una matriz de clasificación de las edificaciones según la época a la que corresponden (ver Tabla 3).

\section{Elaboración de fichas de inventario}

A partir de la matriz de clasificación, se procedió a la elección de la muestra de un ambiente urbano, la Parroquia y 03 viviendas, que aparecen en las siguientes fichas de inventario basadas en las de UNI-FORD con los datos históricos extraídos de libros, folletos y de Registros Públicos, de acuerdo a cada caso. Al final se colocan los valores encontrados. Sin embargo, debido a la escasa información, parte de las fichas no se pudieron completar (ver Figuras 20 y 21).

\section{Interpretación de resultados}

En cuanto a lo arquitectónico y urbano, la Plaza Isabel La Católica es la única que data de la Colonia. Sin embargo, de las 104 construcciones identificadas poseen: 
Tabla 3. Matriz de clasificación de arquitectura doméstica en el Núcleo Histórico de Bellavista.

\begin{tabular}{|c|c|c|c|}
\hline \multicolumn{4}{|c|}{ Época republicana } \\
\hline & Ubicación & Dimensión & Tipo arquitectónico \\
\hline 1 & Av. Bolognesi cdra. 454 & $625 \mathrm{~m} 2$ & Rancho en U \\
\hline 2 & Jr. Elías Aguirre cdra. 502 & $320 \mathrm{~m} 2$ & Rancho Mirador \\
\hline 3 & Av. Bolognesi cdra. 359 & $235 \mathrm{~m} 2$ & Rancho Tipo Zócalo \\
\hline 4 & Av. Bolognesi cdra. 337 & $235 \mathrm{~m} 2$ & Rancho Tipo Zócalo \\
\hline 5 & Av. Bolognesi cdra. 321 & $235 \mathrm{~m} 2$ & Rancho Tipo Zócalo \\
\hline 6 & Av. Bolognesi cdra. 381/373 & $235 \mathrm{~m} 2$ & Rancho Tipo Zócalo \\
\hline 7 & Av. Bolognesi cdra. 180 & $280 \mathrm{~m} 2$ & Rancho con Corredor Lateral \\
\hline 8 & Av. Bolognesi cdra. 1 & $230 \mathrm{~m} 2$ & Rancho con Corredor Lateral \\
\hline 9 & Av. Bolognesi cdra. 114 & $160 \mathrm{~m} 2$ & Rancho con Corredor Lateral \\
\hline 10 & Av. Bolognesi cdra. 125 & $120 \mathrm{~m} 2$ & Rancho con Corredor Lateral \\
\hline 11 & Av. Bolognesi cdra. 139 & $120 \mathrm{~m} 2$ & Rancho con Corredor Lateral \\
\hline 12 & Av. Bolognesi cdra. 599 & $120 \mathrm{~m} 2$ & Rancho en L \\
\hline 13 & Av. Bolognesi cdra. 543 & $120 \mathrm{~m} 2$ & Rancho en L \\
\hline 14 & Av. Bolognesi cdra. 551 & $120 \mathrm{~m} 2$ & Rancho en L \\
\hline 15 & Av. Bolognesi cdra. 573 & $120 \mathrm{~m} 2$ & Rancho en L \\
\hline 16 & Av. Bolognesi cdra. 544 & $120 \mathrm{~m} 2$ & Rancho en L \\
\hline 17 & Av. Bolognesi cdra. 530 & $120 \mathrm{~m} 2$ & Rancho en L \\
\hline 18 & Av. Bolognesi cdra. 637 & $120 \mathrm{~m} 2$ & Rancho Tipo Zócalo \\
\hline 19 & Calle Los Heros cdra. 158/154/150 & $420 \mathrm{~m} 2$ & Rancho Mirador \\
\hline 20 & Calle Los Heros cdra. 128/130 & $110 \mathrm{~m} 2$ & $\begin{array}{l}\text { Rancho con Corredor Lateral } \\
\text { (Villa Dalila) }\end{array}$ \\
\hline 21 & Calle Los Heros cdra. 151 & $500 \mathrm{~m} 2$ & Bomba del Callao $N^{\circ} 15$ \\
\hline 22 & Calle Los Heros cdra. 589 & $180 \mathrm{~m} 2$ & Rancho Tipo Zócalo \\
\hline 23 & Calle Los Heros cdra. 575 & $180 \mathrm{~m} 2$ & Rancho Tipo Zócalo \\
\hline 24 & Calle Los Heros cdra. 585 & $180 \mathrm{~m} 2$ & Rancho Tipo Zócalo \\
\hline 25 & Calle Los Heros cdra. 580 & $156 \mathrm{~m} 2$ & Rancho con Corredor Lateral \\
\hline 26 & Calle Los Heros cdra. 555 & $180 \mathrm{~m} 2$ & Rancho Tipo Zócalo \\
\hline 27 & Calle Los Heros cdra. 565 & $180 \mathrm{~m} 2$ & Rancho Tipo Zócalo \\
\hline 28 & Av. Colina cdra. 684 & $300 \mathrm{~m} 2$ & Rancho Tipo Zócalo \\
\hline 29 & Av. Colina cdra. 680 & $110 \mathrm{~m} 2$ & Rancho Tipo Zócalo \\
\hline 30 & Av. Colina cdra. 690 & $110 \mathrm{~m} 2$ & Rancho Tipo Zócalo \\
\hline 31 & Av. Colina cdra. 672 & $140 \mathrm{~m} 2$ & Rancho Tipo Zócalo \\
\hline 32 & Av. Colina cdra. 660 & $140 \mathrm{~m} 2$ & Rancho Tipo Zócalo \\
\hline 33 & Av. Colina cdra. 631 & $140 \mathrm{~m} 2$ & Rancho Tipo Zócalo \\
\hline 34 & Av. Colina cdra. 669 & $200 \mathrm{~m} 2$ & Rancho en L \\
\hline 35 & Av. Colina cdra. 648 & $200 \mathrm{~m} 2$ & Rancho Tipo Zócalo \\
\hline 36 & Av. Colina cdra. 588/592 & $200 \mathrm{~m} 2$ & Rancho Mirador \\
\hline 37 & Av. Colina cdra. 572 & $120 \mathrm{~m} 2$ & Rancho en L \\
\hline 38 & Av. Colina cdra. 570 & $120 \mathrm{~m} 2$ & Rancho en L \\
\hline 39 & Av. Colina cdra. 550 & $230 \mathrm{~m} 2$ & Rancho en L \\
\hline 40 & Av. Colina cdra. 546 & $120 \mathrm{~m} 2$ & Rancho Tipo Zócalo \\
\hline 41 & Av. Colina cdra. 520 & $180 \mathrm{~m} 2$ & Rancho en L \\
\hline 42 & Av. Colina cdra. 464 & $200 \mathrm{~m} 2$ & Rancho en U \\
\hline
\end{tabular}


devenir Vol. 7, N¹3, ENERO - JUNIO 2020, PP. 31-58 - ESTUDIOS I ISSN 2312-7562 | E-ISSN 2616-4949

UNIVERSIDAD NACIONAL DE INGENIERÍA, LIMA

doi: https://doi.org/10.21754/devenir.v7i13.925

Tabla 3. Matriz de clasificación de arquitectura doméstica en el Núcleo Histórico de Bellavista.

\begin{tabular}{|c|c|c|c|}
\hline \multicolumn{4}{|c|}{ Época republicana } \\
\hline & Ubicación & Dimensión & Tipo arquitectónico \\
\hline 44 & Av. Colina cdra. 407 & $140 \mathrm{~m} 2$ & Rancho con Corredor Lateral \\
\hline 46 & Av. Colina cdra. 413 & $140 \mathrm{~m} 2$ & Rancho con Corredor Lateral \\
\hline 47 & Av. Colina cdra. 415 & $140 \mathrm{~m} 2$ & Rancho con Corredor Lateral \\
\hline 48 & Av. Colina cdra. 421 & $260 \mathrm{~m} 2$ & Rancho en U \\
\hline 49 & Av. Colina cdra. 423 & $260 \mathrm{~m} 2$ & Rancho en U \\
\hline 50 & Jr.. Nicolás de Piérola cdra. 388 & $90 \mathrm{~m} 2$ & Rancho Tipo Zócalo \\
\hline 51 & Jr. Nicolás de Piérola cdra. 384 & $90 \mathrm{~m} 2$ & Rancho Tipo Zócalo \\
\hline 52 & Jr. Nicolás de Piérola cdra. 378 & $90 \mathrm{~m} 2$ & Rancho Tipo Zócalo \\
\hline 53 & Jr. Nicolás de Piérola cdra. 372 & $90 \mathrm{~m} 2$ & Rancho Tipo Zócalo \\
\hline 54 & Jr. Nicolás de Piérola cdra. 356 & $90 \mathrm{~m} 2$ & Rancho Tipo Zócalo \\
\hline 55 & Jr. Nicolás de Piérola cdra. 348 & $90 \mathrm{~m} 2$ & Rancho Tipo Zócalo \\
\hline 56 & Jr. Nicolás de Piérola cdra. 267 & $180 \mathrm{~m} 2$ & Rancho en L \\
\hline 57 & Ca. Nicolás de Piérola cdra. 265 & $180 \mathrm{~m} 2$ & Rancho con Corredor Lateral \\
\hline 58 & Jr. Elías Aguirre cdra. 660 & $100 \mathrm{~m} 2$ & Rancho con Corredor Lateral \\
\hline 59 & Jr. Elías Aguirre cdra. 654 & - & Rancho Tipo Zócalo \\
\hline 60 & Jr. Elías Aguirre cdra. 635 & - & Rancho Tipo Zócalo \\
\hline 61 & Jr. Elías Aguirre cdra. 558 & - & Rancho Tipo Zócalo \\
\hline 62 & Jr. Elías Aguirre cdra. 539 & - & Rancho Tipo Zócalo \\
\hline 63 & Jr. Elías Aguirre cdra. 545 & - & Rancho Tipo Zócalo \\
\hline 64 & Jr. Elías Aguirre cdra. 569 & - & Rancho Tipo Zócalo \\
\hline 65 & Jr. Elías Aguirre cdra. 575 & - & Callejón \\
\hline 66 & Jr. Elías Aguirre cdra. 522 & - & Rancho Tipo Zócalo \\
\hline 67 & Jr. Elías Aguirre cdra. 520 & - & Rancho Tipo Zócalo \\
\hline 68 & Jr. Elías Aguirre cdra. 518 & - & Rancho Tipo Zócalo \\
\hline 69 & Jr. Elías Aguirre cdra. 554 & $190 \mathrm{~m} 2$ & Rancho con Corredor Lateral \\
\hline 70 & Jr. Grau cdra. 515 & $165 \mathrm{~m} 2$ & Rancho Tipo Zócalo \\
\hline 71 & Jr. Grau cdra. 5 & $165 \mathrm{~m} 2$ & Rancho Tipo Zócalo \\
\hline 72 & Jr. Grau cdra. 580 & $165 \mathrm{~m} 2$ & Rancho Tipo Zócalo \\
\hline 73 & Jr. Grau cdra. 584 & $165 \mathrm{~m} 2$ & Rancho Tipo Zócalo \\
\hline 74 & Jr. Grau cdra. 588 & $165 \mathrm{~m} 2$ & Rancho Tipo Zócalo \\
\hline 75 & Jr. Grau cdra. 590 & $165 \mathrm{~m} 2$ & Rancho Tipo Zócalo \\
\hline 76 & Jr. Grau cdra. 562 & $350 \mathrm{~m} 2$ & Rancho Mirador \\
\hline 77 & Jr. Grau cdra. 555 & $265 \mathrm{~m} 2$ & Rancho en L \\
\hline 78 & Jr. Grau cdra. 525 & $265 \mathrm{~m} 2$ & Rancho en $\mathrm{L}$ \\
\hline 79 & Jr. Grau cdra. 589 & $265 \mathrm{~m} 2$ & Rancho en L \\
\hline 80 & Jr. Grau cdra. 569 & $265 \mathrm{~m} 2$ & Rancho en L \\
\hline 81 & Jr. Grau cdra. 485 & $265 \mathrm{~m} 2$ & Rancho en U (Villa Margarita) \\
\hline 82 & Jr. Grau cdra. 383 & $225 \mathrm{~m} 2$ & Rancho Tipo Zócalo \\
\hline 83 & Jr. Grau cdra. 390 & $120 \mathrm{~m} 2$ & Rancho Tipo Zócalo \\
\hline 84 & Jr. Grau cdra. 350 & $170 \mathrm{~m} 2$ & Rancho en L \\
\hline 85 & Jr. Grau cdra. 340 & $170 \mathrm{~m} 2$ & Rancho en $\mathrm{L}$ \\
\hline 86 & Av. Saenz Peña cdra. 1480 & - & Villa Victoria \\
\hline 87 & Av. Buenos Aires 1670 & - & Rancho con Corredor Lateral \\
\hline
\end{tabular}




\begin{tabular}{|c|c|c|c|}
\hline \multicolumn{4}{|c|}{ Época de transición. } \\
\hline & Ubicación & Dimensión & Tipo arquitectónico \\
\hline 1 & Jr. Los Heros 262/256 & $500 \mathrm{~m} 2$ & Unifamiliar (Villa Rebeca) \\
\hline 2 & Jr. Grau 439 & - & Multifamiliar (Quinta Santa Isabel) \\
\hline 3 & $\begin{array}{l}\text { Jr. Colina } 301 / 315 \text { y } 315-\mathrm{A} / 321 \text { y } \\
321-\mathrm{A} / 331 / 337\end{array}$ & 0 & Multifamiliar (Viviendas en serie) \\
\hline 4 & Jr. Colina 397 & 0 & Unifamiliar \\
\hline 5 & Jr. Grau 329 & $350 \mathrm{~m} 2$ & Unifamiliar \\
\hline 6 & Jr. Grau 335 & $350 \mathrm{~m} 2$ & Unifamiliar \\
\hline 7 & $\begin{array}{l}\text { Av. Buenos Aires 1806/1812/1820 } \\
/ 1824 / 1828 / 1867 / 1836 / 1846\end{array}$ & - & Multifamiliar (Viviendas en serie) \\
\hline 8 & Av. Buenos Aires 1858 & - & Multifamiliar (Quinta Santa Carlos) \\
\hline 9 & $\begin{array}{l}\text { Av. Buenos Aires } \\
1650 / 1652 / 1654 / 1656\end{array}$ & - & Multifamiliar \\
\hline 10 & Av. Guardia Chalaca 1580 & - & Unifamiliar \\
\hline 11 & Jr. Bolognesi 200 & - & Unifamiliar \\
\hline 12 & Jr. Bolognesi 205 & - & Unifamiliar \\
\hline \multicolumn{4}{|c|}{ Época moderna. } \\
\hline & Ubicación & Dimensión & Tipo arquitectónico \\
\hline 1 & Jr. Grau cdra. 2 & $1000 \mathrm{~m} 2$ & Multifamiliar \\
\hline 2 & Av. Bolognesi cdra. 232 & $350 \mathrm{~m} 2$ & Unifamiliar \\
\hline 3 & Av. Bolognesi cdra. 239 & $500 \mathrm{~m} 2$ & Unifamiliar \\
\hline 4 & Av. Bolognesi cdra. 296 & $500 \mathrm{~m} 2$ & Unifamiliar \\
\hline 5 & Av. Bolognesi cdra. 274 & $350 \mathrm{~m} 2$ & Unifamiliar \\
\hline
\end{tabular}

- Alto valor histórico; ya que existen 87 casonas de la época Republicana, 12 edificaciones de la época de Transición con estilos como el Art-Decó, el estilo Buque y el Tudor, y 05 viviendas de estilo Moderno. Asimismo, la zona de estudio de Bellavista representa una parte importante de la historia para el Callao y Lima al haber sido creada para ser el Nuevo Puerto del Callao después de 1746 (ver figura 22).

- Alto valor cultural; ya que estas viviendas representan las distintas épocas por las que pasó el distrito y podemos encontrar varias de ellas.

- Bajo valor social; a excepción de la Iglesia y la Plaza, los otros ejemplares carecen de significado para los vecinos, sea por desconocimiento o por las transformaciones que muchos de ellos realizan cambiando por completo las construcciones originales.

- Mediano valor artístico; en la mayoría de las fachadas de la época de Transición y época Republicana, los detalles característicos de estos estilos están siendo reemplazados por remodelaciones modernas sin ningún tipo de respeto o referencia a su arquitectura original. Sin embargo, en la Iglesia, en Villa Victoria y en algunas casonas aún se conservan los detalles y ornamentos originales que datan del siglo XIX y evidencian su valor artístico. 
devenir Vol. 7, N¹3, ENERO - JUNIO 2020, PP. 31-58 - ESTUDIOS I ISSN 2312-7562 | E-ISSN 2616-4949

UNIVERSIDAD NACIONAL DE INGENIERÍA, LIMA

UNIVERSIDAD NACIONAL DE INGENIERIA

FACULTRD CE ARQUITLCTURR, URISANISMO YARTLS

TALIFR DEINUFETIGACKIN EN HISTOFIA DE LA ARRUITECTIAA I

"INUENTARIO DEL PATRIMONIO MIONLMENTAL INMUEBLE QE BELLAVISTA"
N' DE FI매A

1

L. DERTFKaTON

\begin{tabular}{|c|c|c|c|}
\hline 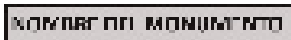 & 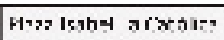 & & \\
\hline CóvGo & & EXISTENCLA ACTUAL & $\vdots \mathbf{i}$ \\
\hline TPO GENE TCO & 4 malsnoc $\mathrm{dr} \times \mathrm{A}$ & ПРОЕЕРЕС|АСО & P: \\
\hline
\end{tabular}

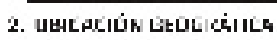

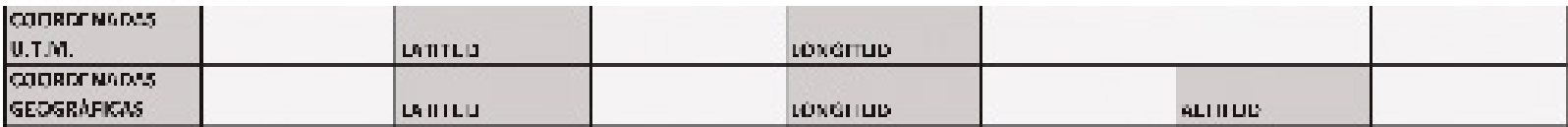

3. UECACION PO_ITICA

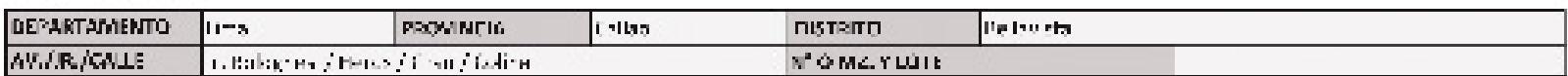

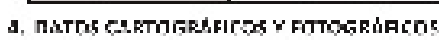

\begin{tabular}{|c|c|c|c|}
\hline & 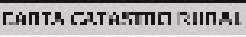 & CAMTAIGN & 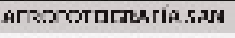 \\
\hline \multicolumn{4}{|l|}{ SolOLO } \\
\hline \multicolumn{4}{|c|}{ XUMERO I IN } \\
\hline \multicolumn{4}{|l|}{$\operatorname{tsc} \Omega$} \\
\hline FECHA & & & \\
\hline
\end{tabular}

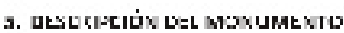

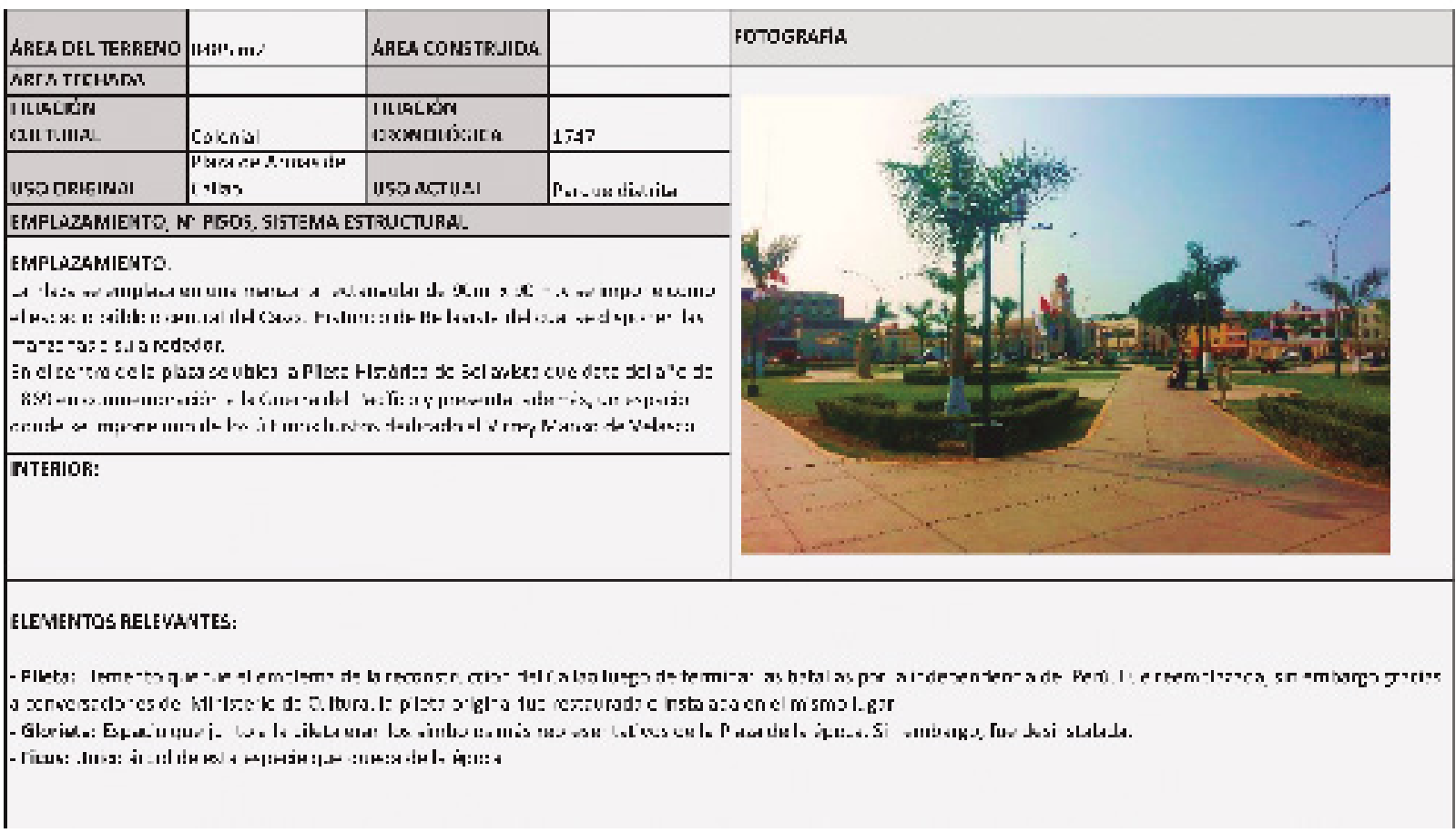

Figura 20. Muestra de modelo de ficha realizada para ambiente urbano: Plaza Isabel La Católica. Parte I. Elaboración propia, 2016.

- Mediano valor arquitectónico; como edificaciones independientes, la mayoría de los ejemplares puede que no reúnan las características para poseer un alto valor arquitectónico debido a sus dimensiones o por las modificaciones exteriores y/o interiores que han estado atravesando, sin embargo aún existen ejemplares que muestran una distribución y relaciones espaciales propias de la casa urbana de patio Colonial. 
6. IDENTIFICACIÓN

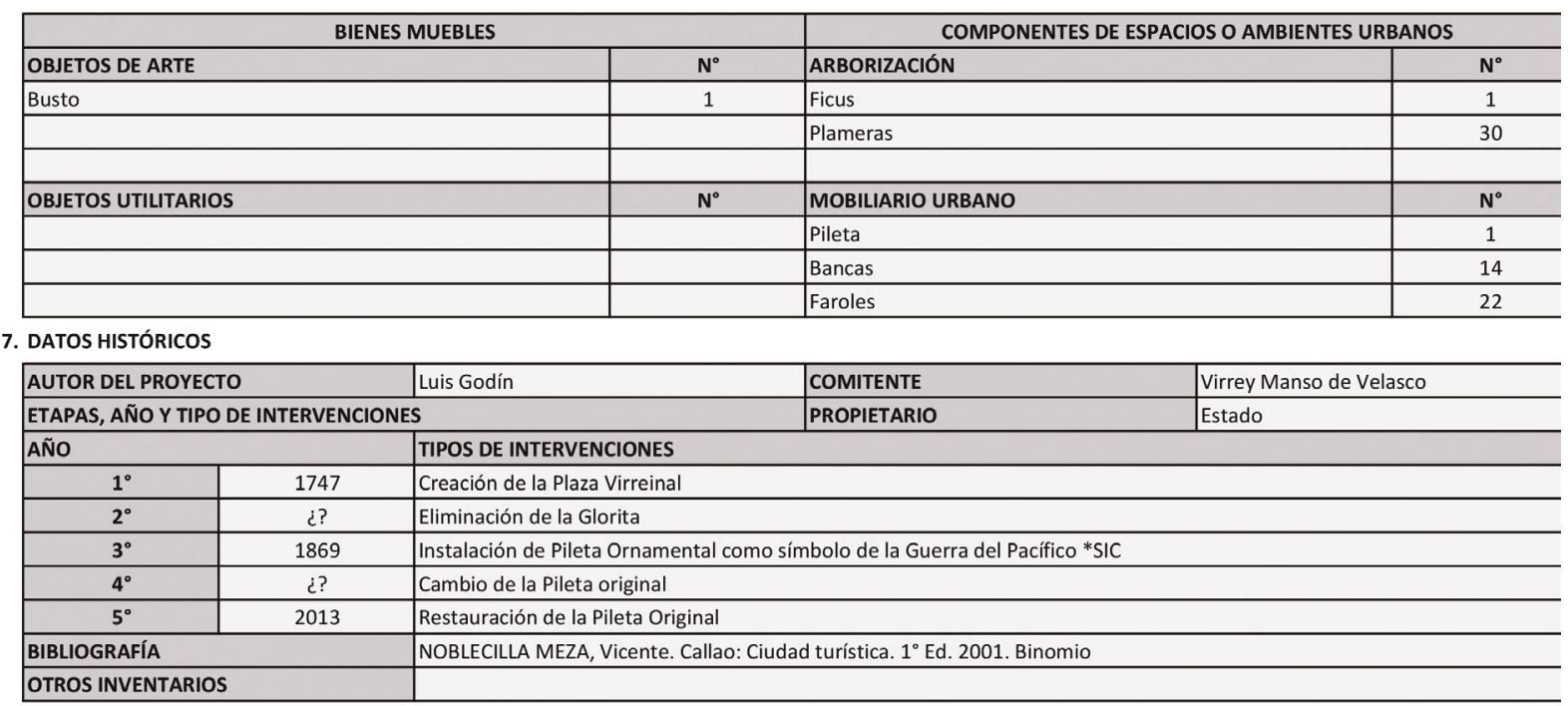

8. DATOS TÉCNICOS

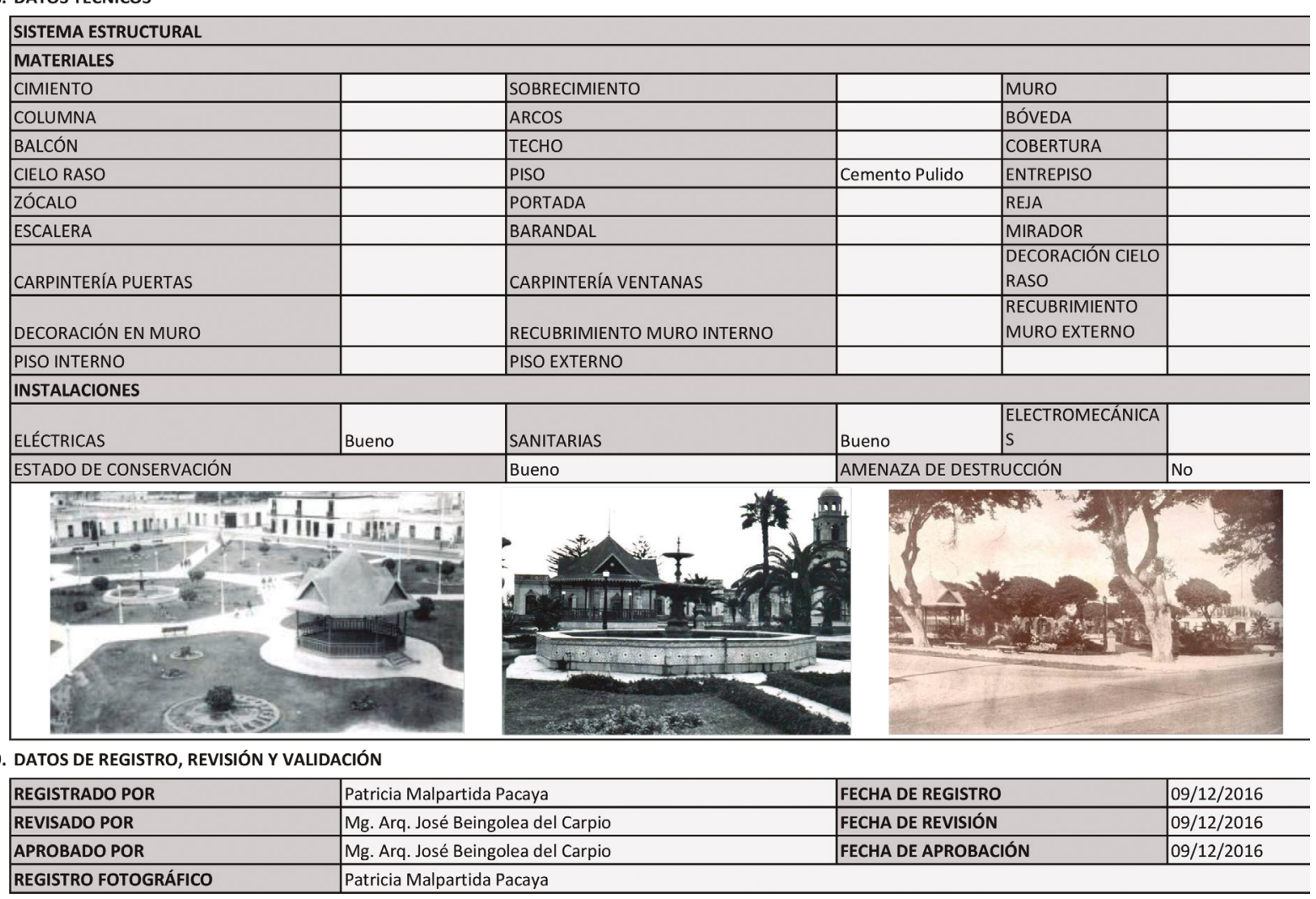

Figura 21. Muestra de modelo de ficha realizada para ambiente urbano: Plaza Isabel La Católica. Parte II. Elaboración propia, 2016.

- Alto valor contextual; como se mencionó anteriormente, si bien como edificaciones independientes no posean un gran valor que justifique una declaración, como conjunto sí forman un paisaje particular y una imagen que caracteriza a la zona, como es el caso del Jr. Bolognesi cuadra 3 y el Jr. Grau cuadra 5, calles donde se aprecia una serie de viviendas propias de su época o la plaza Isabel La Católica y los frentes que la rodean. 

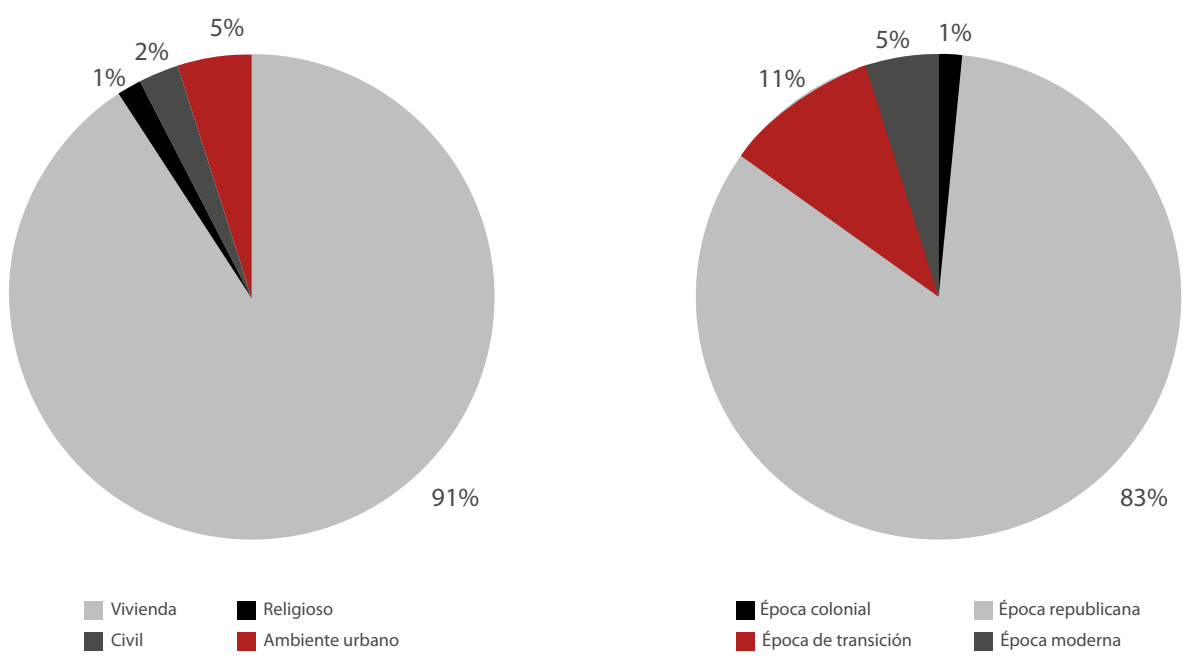

Figura 22. A la izquierda, porcentajes de tipos arquitectónicos identificados enel área investigada. A la derecha, porcentajes de la cantidad de viviendas según cada época. Elaboracion propia, 2019.

\section{Conclusiones}

Bellavista es un distrito cuya historia empieza después del sismo y maremoto de 1746 que dejó al antiguo puerto del Callao totalmente destruido. Con el fin de evitar otra destrucción por alguna catástrofe similar, el Virrey Manso de Velasco, Conde de Superunda decide reconstruirlo en tierras más elevadas, conocidas antes como "buena vista', y que debido a su ubicación estratégica, pudiera convertirse en una zona residencial y política, así como almacén del nuevo puerto.

El Virrey encargó el diseño de este nuevo pueblo al famoso matemático francés Luis Godín, cuyo objetivo fue crear un espacio que brinde protección y pueda ser evacuado en caso de desastres naturales con el ensanche de las calles a unos 10 metros, teniendo así una traza a modo de cuadrícula con la misma lógica que el centro histórico de Lima: una plaza central con los edificios más importantes como la iglesia y la antigua Casa del Virrey. También se propuso limitar la altura de las edificaciones y de sus muros exteriores.

Por lo tanto, su valor urbano radica en su traza y su emplazamiento. La traza data desde la época de la Colonia y se mantiene intacta en su mayor parte. En cuanto a su emplazamiento, el factor principal fue ubicar el nuevo puerto en una zona de mayor altura y entre las dos vías principales de la época: el antiguo camino hacia Lima por el norte y el camino hacia Maranga por el sur, orientándose la traza perpendicular al borde marino para tener el mar como parte del paisaje.

En cuanto a la morfología urbana, su traza es cuadricular; sus manzanas son cuadradas, rectangulares, triangulares y trapezoidales; la parcelación es irregular y distorsionada del tipo " $\mathrm{X}$ ", " $\mathrm{H}$ " e " $\mathrm{Y}$ ", como se puede apreciar en la figura 16; su textura actualmente se está formando y tiende a ser cerrada pero el grano sigue siendo fino con tendencia a ser grueso.

Entre los ambientes urbanos más importantes tenemos la plaza Isabel La Católica, la única evidencia de la época colonial, y el Jirón Bolognesi que, según mi opinión basada en lo encontrado, pudo ser la calle principal del Núcleo Histórico fundacional por conectarse con el antiguo camino hacia Lima y ostentar esos grandes sauces en gran parte de su tramo hacia la plaza central. Asimismo, es una de las calles que me- 
jor evidencia su historia con sus tres periodos arquitectónicos: Republicano, época de Transición y Moderno.

En cuanto a los tipos arquitectónicos encontrados, según los periodos, tenemos: Republicano, donde están las casas tipo rancho y la fachada de la Empresa Nacional de Puertos que es típica de las bodegas de la época. Del periodo de Transición encontramos viviendas unifamiliares y multifamiliares con estilos Art-Decó, Buque y Tudor; del mismo modo habría que mencionar al antiguo cine de Bellavista, a la parroquia San José de Bellavista y al estadio Telmo Carbajo, cuya fachada ya ha sido declarada como Bien integrante del Patrimonio Cultural de la Nación por el Instituto Nacional de Cultura (INC). Por último, de la época Moderna encontramos tipos de arquitectura doméstica como viviendas unifamiliares y multifamiliares y también arquitectura civil como la actual Municipalidad de Bellavista.

Finalmente, los principales valores del Núcleo Histórico de Bellavista son de carácter histórico, cultural y contextual y crean en conjunto un paisaje característico que no se encuentra en ninguna otra parte del Callao ni de Lima. Actualmente, este Núcleo Histórico se encuentra amenazado por un proceso de deterioro por la densificación que degrada su arquitectura original y la falta de regulación por las entidades competentes. A esta situación, hay que añadir la ausencia de proyectos de recuperación, educación y sensibilización, que impide que la mayoría de los vecinos valore su zona histórica y tome conciencia de que este deterioro que se viene dando en los últimos años puede ser irreversible.

Considero que aún estamos a tiempo de poder salvar la historia y la esencia de este distrito que, pese haber fracasado como primer puerto, tuvo un importante rol histórico que merece ser conocido.

\section{Referencias}

Ballart i Hernández, J., Fullola i Pericot, J.M., \& Petit i Mendizábal, M. (1996). El valor del patrimonio histórico. Complutum, Extra 6(2), 215-224.

Bertrand, M. (1984). Casa, Barrio, Ciudad: Arquitectura del Hábitat urbano. Barcelona: Gustavo Gili.

Capel, H. (2002). La Morfología de las ciudades. 1. Sociedad, cultura y paisaje urbano. Barcelona: Ediciones del Serbal.

Capitel, A. (2009). Metamorfosis de Monumentos y reorías de restauración. Alianza Editorial

Comité Peruano del Consejo Internacional de Monumentos y Sitios (2014). Norma A.140. Bienes Culturales Inmuebles. Recuperado de http://peru.icomos.org/Norma\%20A\%20140.pdf

Congreso de la República del Perú. (2011) Ley General del Patrimonio Cultural. Recuperado de http://www2.congreso.gob.pe/sicr/comisiones/2011/com2011 cultura.nsf/pubsfoto/ 6FAA4E54D3AD179E05257911006D5D23/\$FILE/REGLAMENTO_LEY_GENERAL_PATRIMONIO_CULTURAL.PDF

Cullen, G. (1981). El Paisaje Urbano. Tratado de Estética urbanística. Barcelona: Blume

Darío, M. (1904). El Callao en la época del coloniaje, antes y después de la catástrofe de 1746. Callao, Callao.

Dirección Desconcentrada de Cultura del Callao. (2017). Callao, Patrimonio, Historia e Identidad. Huaca Culebras: Una propuesta de política cultural para el desarrollo. Ministerio de Cultura. Lima, Perú.

Dirección Desconcentrada de Cultura del Callao. (2016). Recuperado de http://www.cultura. gob.pe/es/ddc/callao

Gambetta, N. (1936). Cosas del Callao. Lima, Perú.

García, J. (1980). La Arquitectura en el Virreinato y la República. Lima, Perú: Editorial Juan Mejía Baca.

Hayakawa, J. (2012). Restauro UNI, Breve antología de textos de Restauración del Patrimonio Monumental Edificado. Lima, Perú: Universidad Nacional de Ingeniería, Editorial Universitaria. 
devenir Vol. 7, N¹3, ENERO - JUNIO 2020, PP. 31-58 - ESTUDIOS I ISSN 2312-7562 | E-ISSN 2616-4949 UNIVERSIDAD NACIONAL DE INGENIERÍA, LIMA

doi: https://doi.org/10.21754/devenir.v7i13.925

Hernández, Y. (2010). Importancia del turismo en la recuperación del Centro Histórico del Callao. Lima, Perú: Facultad de Arquitectura, Urbanismo y Artes, Universidad Nacional de Ingeniería

Lynch, K. (1970). La Imagen de la ciudad. $2^{\circ}$ Ed. Buenos Aires: Infinito

Maderuelo, J. (2010). Paisaje y Patrimonio. Series Pensar el Paisaje. Madrid: Abada editorial.

Malpartida, P. (2019). Callao, Patrimonio, Historia e Identidad. Huaca Culebras: Una propuesta de política cultural para el desarrollo. Devenir, 5 (10), 182.

Mattos-Cárdenas, L. (2004). Urbanismo Andino e Hispanoamericano. Ideas y realizaciones. Lima, Perú: Facultad de Arquitectura Urbanismo y Artes - Universidad Nacional de Ingeniería.

Ministerio de Cultura. (2019). Procedimiento para la Declaración de un Monumento Nacional y requisitos mínimos para presentar una solicitud de declaración. Recuperado de http:// www.arquitecturamop.cl/Patrimonio/Documents/procedimientos.pdf

Ministerio de Educación, Cultura y Deporte. (2001). El Urbanismo en el Nuevo Mundo. El ejemplo peruano. Madrid, España: Secretaría General Técnica.

Montañez, M. (2016). Gestión y valoración del Patrimonio histórico inmueble en el Centro Histórico del Callao. Devenir, 3 (6), 98-124.

Municipalidad de Bellavista. (2016). Recuperado de http://www.munibellavista.gob.pe

Municipalidad Provincial del Callao. (2010). Informe final del Plan de Desarrollo Urbano de la Provincia Constitucional del Callao: Análisis estratégico y formulación del modelo de desarrollo y propuesta específica (Zonificación Urbana) 2011 - 2022. Recuperado de http://www. municallao.gob.pe/contenidosMPC/downloads/documento/desarrollo/caracterizacion.pdf

Noblecilla, V. (2001). Callao, Ciudad turística. Lima, Perú: Binomio.

Pérez, R. (2012). Bellavista, Historia y Leyenda de la Ciudad Jardín. Fascículo 3. Bellavista, Callao: Albatros.

Programa de Inventario de Monumentos Históricos Nacionales. (2016). Recuperado de http:// www.ahter.org/pdf/FNAFichaBovedasUspallata.pdf

Quevedo, C. (2016). Criterios para la Conservación y Revalorización del Urbanismo Colonial Hispanoamericano: Estudio de caso. Devenir, 3 (6), 9-30.

Quiroz, F. (2007). Historia del Callao: De puerto de Lima a Provincia Constitucional. Lima, Perú: Fondo Editorial del Pedagógico San Marcos.

Ríos, M. (2014). Urbanismo Barroco en Lima Virreinal: Hacia la recuperación de la Calle de la Amargura. Devenir, 1 (2). 40-58.

Sánchez, F. (1989). Historia del Callao: Pasado, presente y futuro. Lima, Perú: Consejo Nacional de Ciencia y Tecnología.

Sgroi, A. (2009). Morfología urbana: paisaje urbano. Argentina: Universidad de La Plata. Programa de investigaciones del Taller.

Universidad Nacional de Ingeniería - Fundación Ford (1988) Inventario del patrimonio monumental de Lima: valles de Chillón, Rímac y Lurín. Tomo IV Época virreinal. Lima, Perú: Facultad de Arquitectura Urbanismo y Artes - Universidad Nacional de Ingeniería.

Vidal, M. (2013). Evolución tipológica de las viviendas en el distrito de Barranco-Lima. Universidad San Martín de Porres.

Villagrán, J. (1988). Teoría de la Arquitectura. 1 Vol. México: Universidad Nacional Autónoma de México. 